\title{
استخلام مواقع التواصل الاجتماعي وأثره على القيم الاجتماعية لدى طلبة جامعة عمان الأهية
}

\author{
د. اعوثر سلامة جبارة

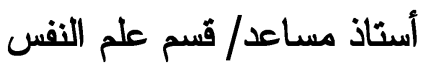

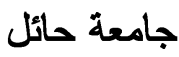

\author{
د. دونية عطا صوالحة \\ أستاذ مشارك/قسم علم النفس و التربية الخاصة \\ جامعة عمان الأهلية
}

\section{المانغnص}

هدفت هذه الدراسة إلى معرفة أثر استخدام مواقع التواصل على تغيير القيم الاجتماعية لدى طلبة جامعة عمان الأهلية، وكذلك التعرف إلى الآثار الإيجابية والسلبية المترتبة على هذا الاستخدام، وعلاقته

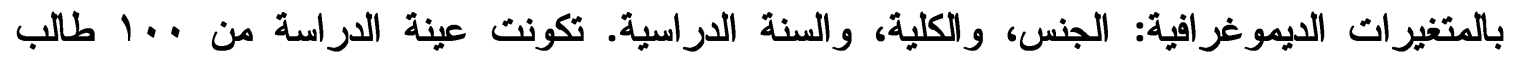
وطالبة من طلبة جامعة عمان الأهلية. تم استخدام وتطبيق استبانة من إعداد الباحثتين بعد حساب الصدق

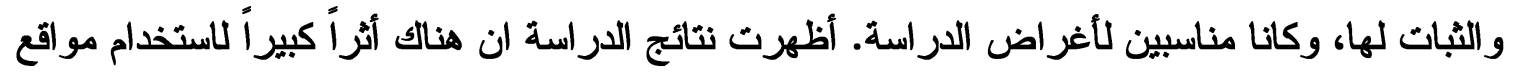

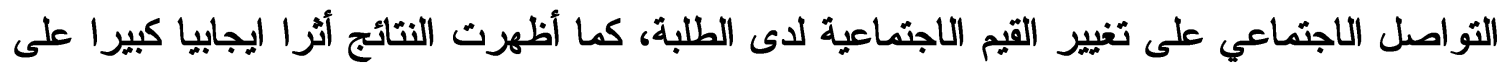

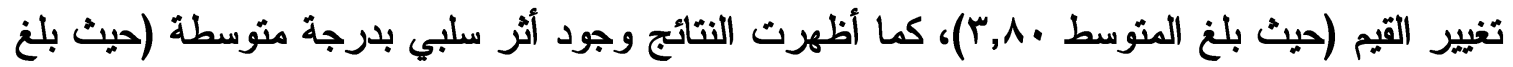

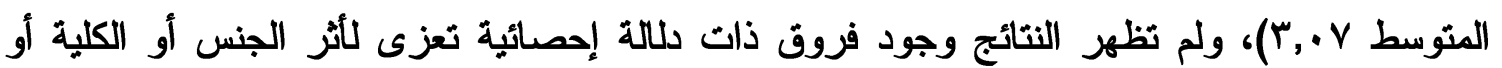

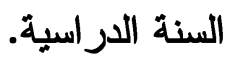

الكلمات المقتاحية: شبكات التو اصل الاجتماعي، القيم الاجتماعية، طلبة جامعة عمان الأهلية. 
The relation between social values and Browsing social media networks on of Al Ahliyyah Amman University students under certain values

\begin{abstract}
:
This study was conducted to find out the impact of browsing social media websites on the social values of Amman Al Ahliyah University students. And to identify the positive and negative impacts of this browsing, and determine if it's influenced by the demographic values: gender, faculty and academic year.

The sample of the study consisted of 100 students (males and females) selected from Al Ahliyyah Amman University. A questionnaire was prepared and applied by the two researchers after evaluating the validity and reliability, which met the rationale of their study. The findings of the study showed that there was a large impact of browsing these sites in changing students' social values. And the results showed a large positive impact on the social values (with mean of 3.80 ), and a moderate negative impact (with mean of 3.07). There were no statistically significant differences could be attributed to gender or faculty nor the academic year.
\end{abstract}

Keywords:

Social media networks, social values, Al Ahliyah Amman University students. 


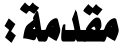

تهدف البرامج التربوية والتعليمية في المؤسسات التربوية المختلفة من مدارس وجامعات الى

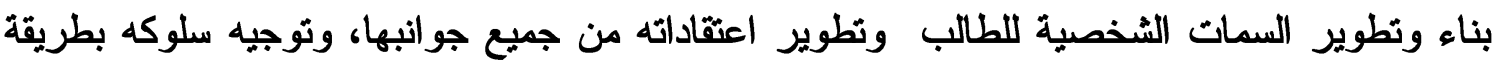

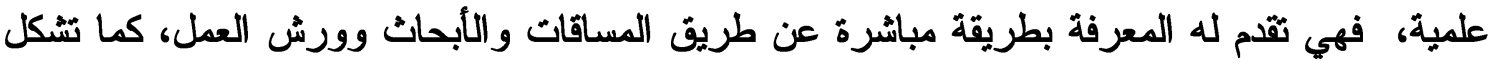

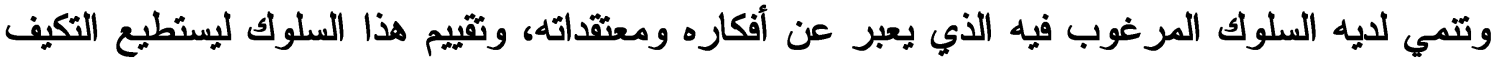

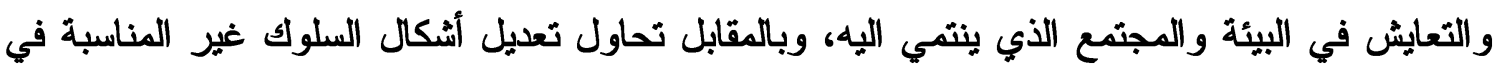
بيئته ومجتمعه، كما تقدم له طرق التفكير العلمي ليستطيع اختيار واعتتاق القيم المناسبة بعد تغيرات

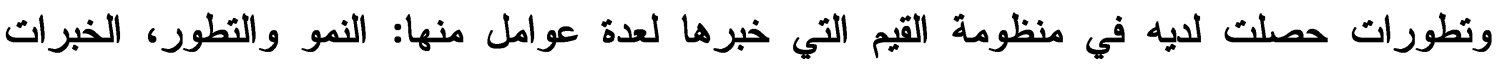
السابقة، والممارسات السلوكية المكتسبة.

ويرى التربويون و الفاسفة والمفكرون بأن ثقافة الأسر والمجتمعات والأمم تثأثر بقيمها، فاختلاف

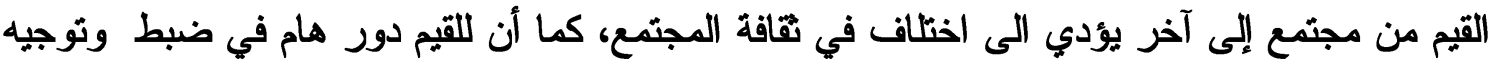
السلوك الإنساني والتتبؤ بسلوكات جديدة للإنسان تتماشى مع قيمه وتدعمها وتطورها بالاتجاه المناسب

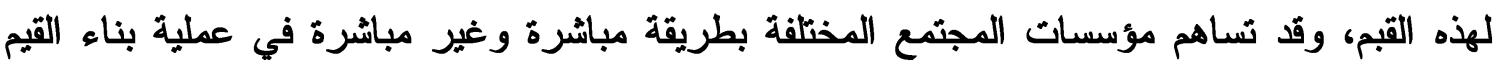

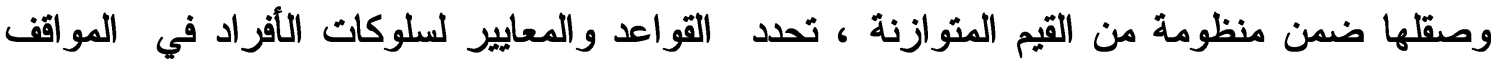

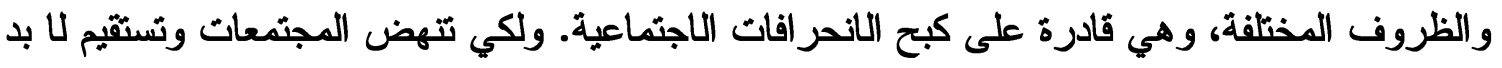
من التركيز على القيم الآيجابية وتطويرها، لما لها من أهمية على مستوى الإنسانية، فهي تحارب العنف

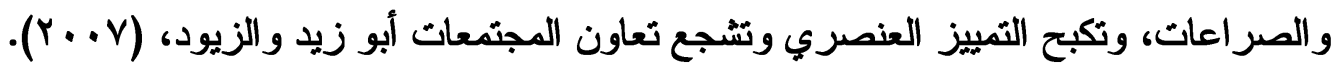

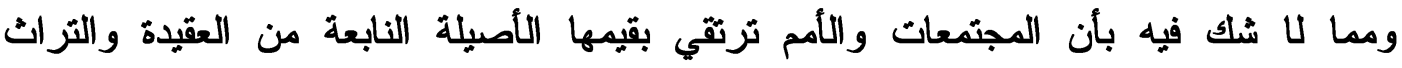
الحضاري، بمساهمة المؤسسات التربوية المختلفة. ان من أهم المؤسسات التربوية التي تهتم بغرس القيم

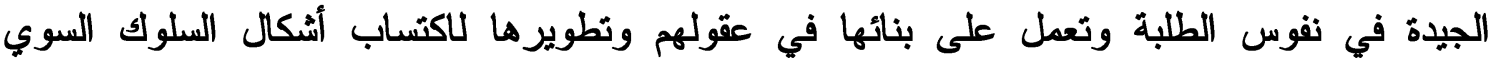

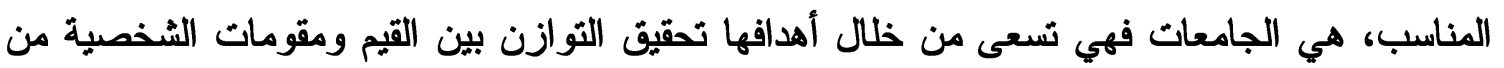

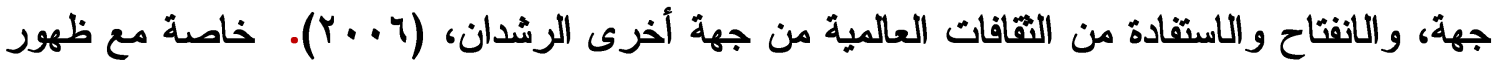

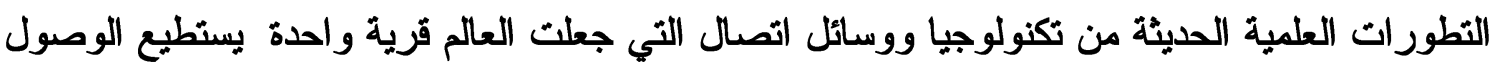

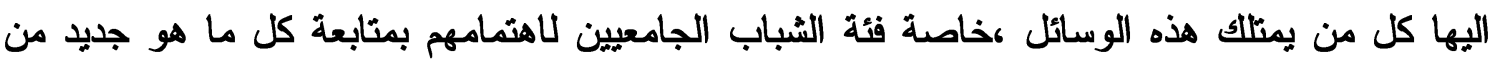

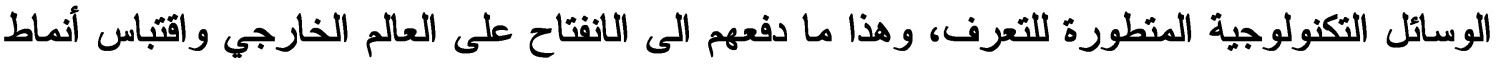

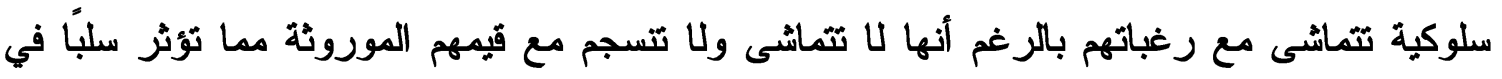

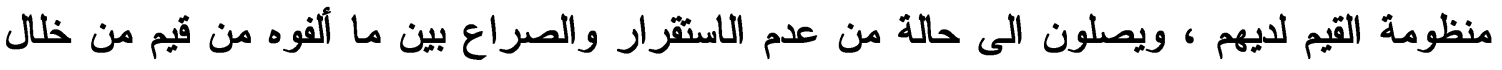


خبراتهم وتراثهم الثقافي ، وبين ما تفرضه عليهم الظروف الجديدة التي يعيشونها والمتغيرات الحياتية التي خبروها حديثًا بفعل وسائل الثو اصل الاجتماعي و التكنولوجيا. فقد أصبحت وسائل التواصل الاجتماعي سمة من سمات العصر الحالي وأصبحت لها أثر كبير على فكر المجتمعات فهي تعتبر ذو حدين، فقد تكون وسيلة لتعزيز السلوك الإيجابي داخل المجتمع من خلال التعرف على كل ما هو جديد في مجال العلوم وتبادل الخبرات العلمية في جميع المجالات وعلى لإلى

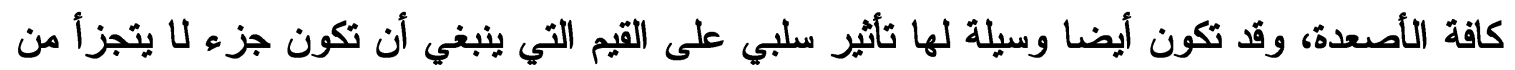

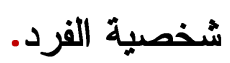

ويرى البسطامي، 2008 أن الظروف الاجتماعية والاقتصادية كالتفكك الأسري، والعيش في

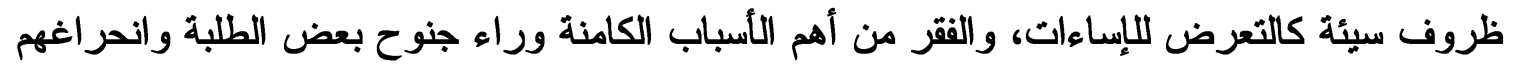
عن مسار القيم التي كانت سائدة في مجتمعاتهم، حيث تؤثر الممارسات والخبرات السفات البية التي عاشوها في ظل تلك الظروف الصعبة من وجهة نظرهم الى عدم فهم و وادراك قيم المجتمع وأحيانا استبدال هذه فئه

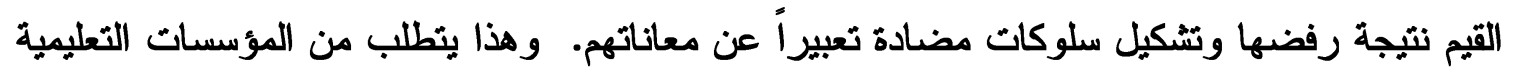
و الاجتماعية تخفيف هذه المعاناة والوقوف على نتائجها لإجراء الحلول المناسبة، ولتوضيح أنواع ونهاع وأشكال

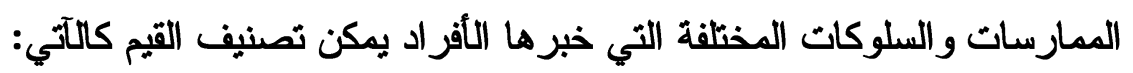

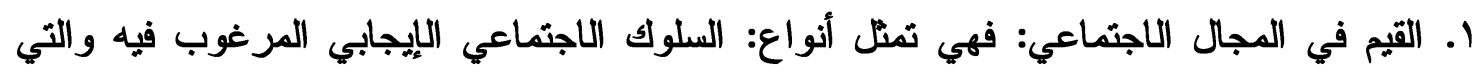

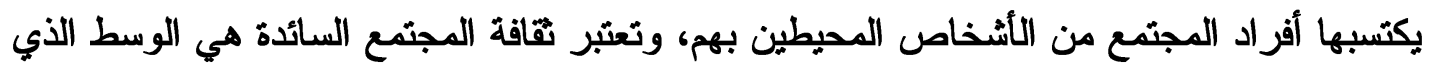

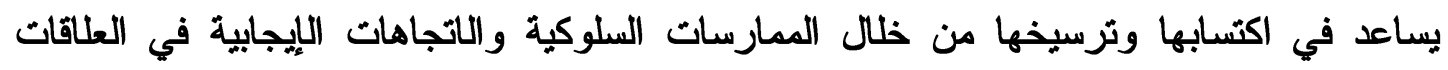

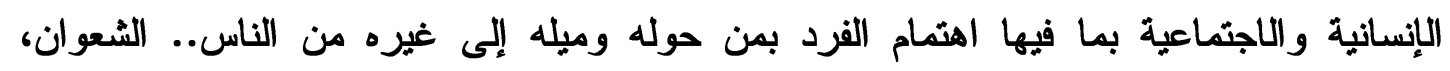

r. القيم في المجال الاقتصادي: تمثل أنواع: السلوك التي نقود الأفراد الى المنفعة المادية والمنفعة

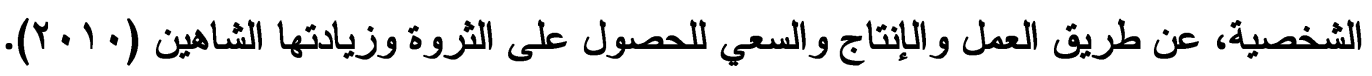

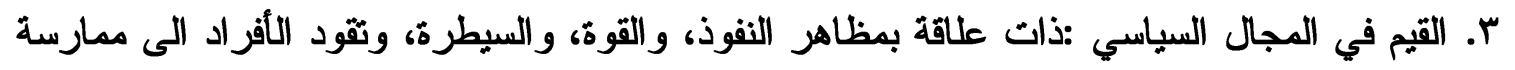
سلوكات تتعلق بالنشاط السياسي، وحل مشكلات الاخرين. طهطاوي (1997 (19).

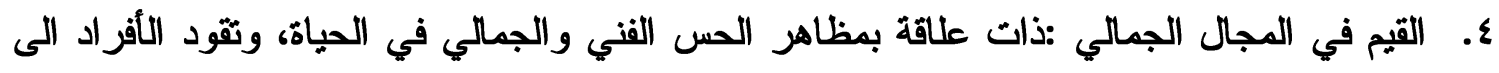
ممارسة سلوكات تتعلق بالفن وجمال الذوق والابتكار، والاهتمامات الفنية والجمالية. الجلاد $\cdot(r \cdot \Lambda)$ 
ه. القيم في مجال الفكر والعقائد: ذات علاقة بمظاهر الدين والمعتقدات والقضايا الروحية والدينية

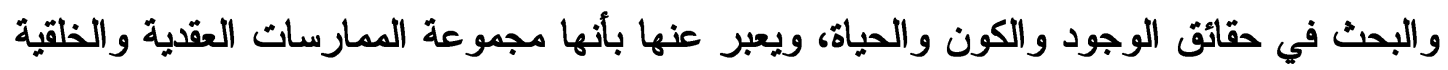
التي توجه السلوك، وتشكل شخصية الفرد، وتحدد طبيعة سلوكه وتوجهاته وممارساته تجاه الآخرين

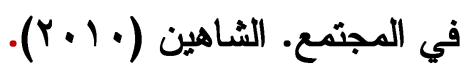

ومهما كانت مسميات هذه التصنيفات، فهي تشتمل على ثلاثة مكونات أساسية: أولها مايتعلق بالجانب المعرفي -العقلي؛ ويتضمن استكشاف القيم والتعرف عليها من خلال النظر في البدائل الممكنة

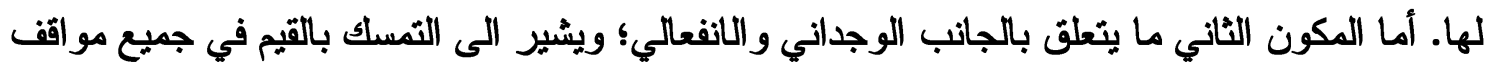

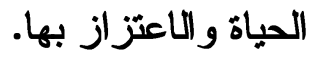

أما بالنسبة للمكون الثالث الآدائي؛ يترجم القيم الى ممارسة واقعية في الحياة اليومية، وهذا يدفع والثاء الأفر اد والجماعات والأمم الى بناء منظومة قيمية تساعدها على اكتشاف أسباب القوة والتطور والبقاء.

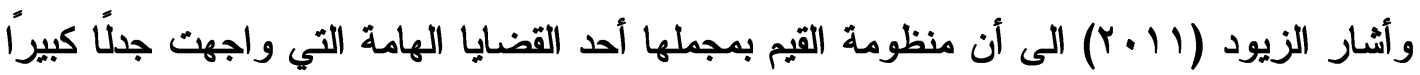
نتيجة المستجدات والتغيرات في التي حصلت في العصر الحديث، وما رافقها من تغيرات هاتئلة فئلة في مجال التكنولوجيا المعلوماتية، وما أحثثه هذه المستجدات من تأثير في البنية الثقافية والاجتماعية ونية

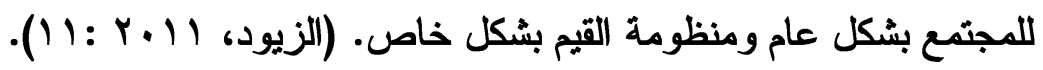
وقد اختلف الباحثُون فيما توصلوا إليه حول الآثار المرافقة لاستخدام شُبكات التواصل الاجنماعي

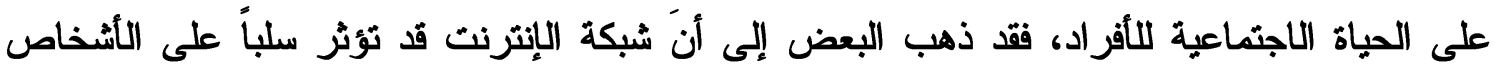

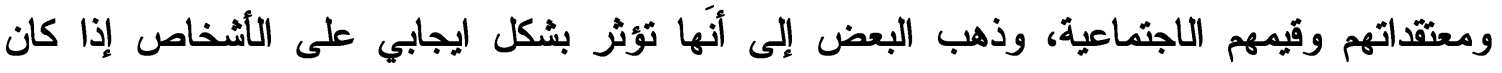

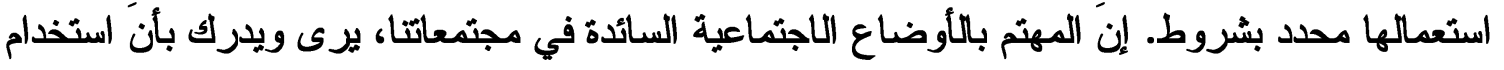

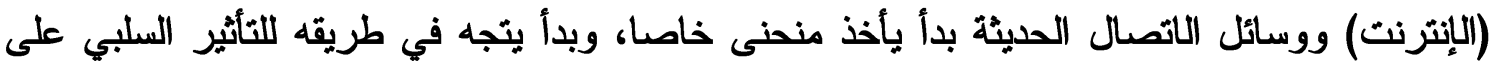

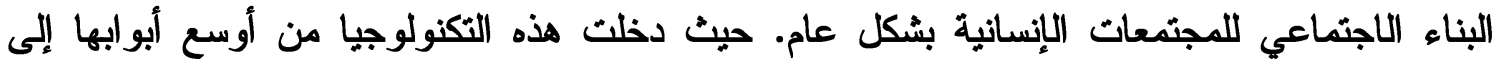
المجتمعات المحلية حاملة معها بعض من التأثيرات الاجتماعية والنفسية كنتيجة حتمية فرضتها عملية

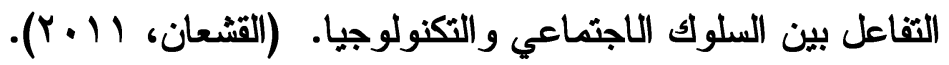

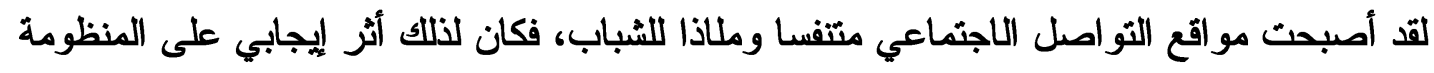
القيمية كما إنها أججت في نفوسهم الحماس للثفاعل مع الكثير من القضايا القيمية والفكرية والسياسية و الدينية والصحية والاجتماعية التي تركز على الجانب الإنساني المرتكز على ترسيخ القيم لايهم. كما

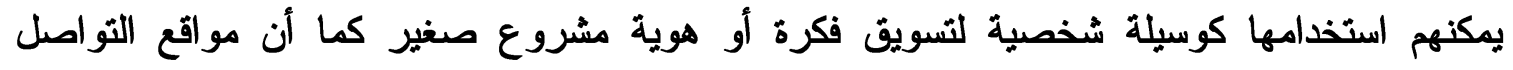
الاجتماعي أداة جيدة تمكن مشتركيها من توظيف أفضل الوسائل والطرق التربوية لتعديل السلوكات 
السلبية ، فمواقع التواص الاجتماعي تعمل على إحداث تغييرات وتأثيرات إيجابية في الفكر والسلوك

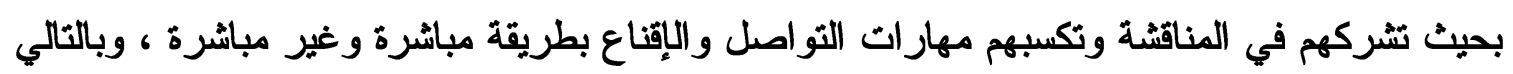

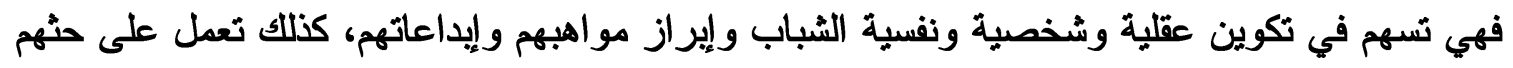

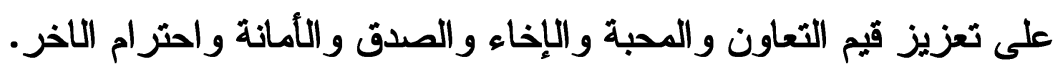

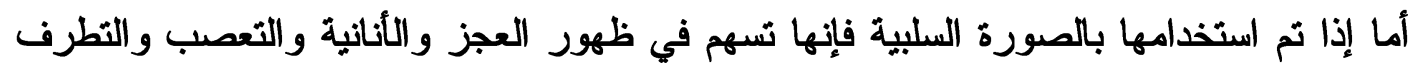

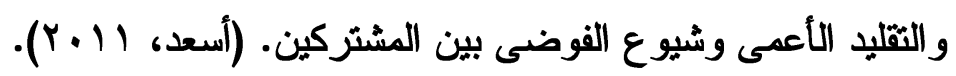
وتعتبر شبكات الثواصل الاجتماعي من أكبر مغريات الشباب، وأكثرها خطورة عليهم، بل وباتت

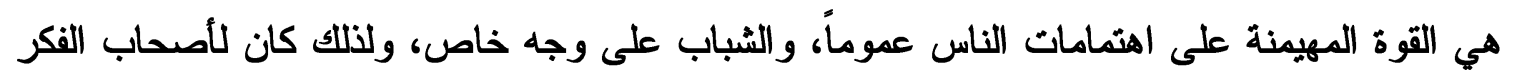

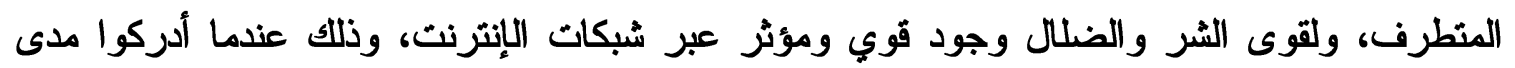

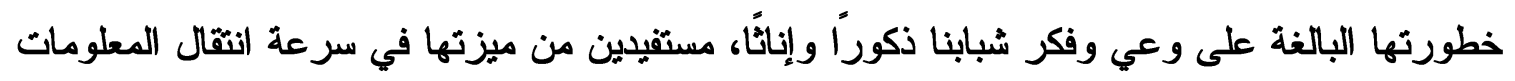

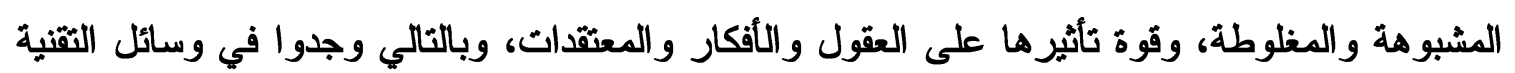

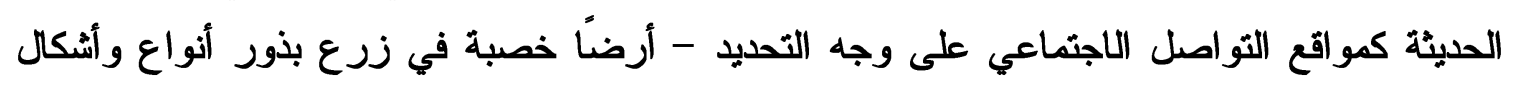

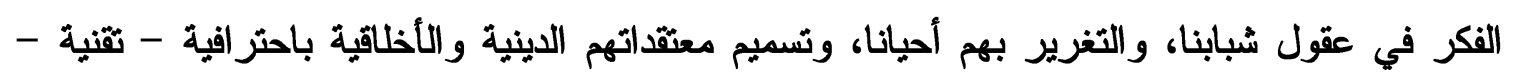
عالية ومدروسة. كذلك تؤثز وسائل الاتصال بطريقة سلبية من خلال الثقافات المفتوحة على بعضها البعض وممارسة

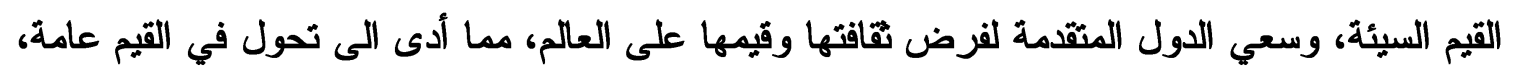
و القيم الاجتماعية بشكل خاص، لرغبة الشباب الجامعي في التجديد والتغيير بممارسة سلوكات غير ولفير

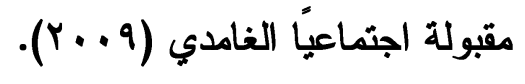
أما ما يتعلق بآلآثار الإيجابية فقد اتفق العلماء والمفكرون من رجال الاجتماع والهاع الاتصال على أهمية

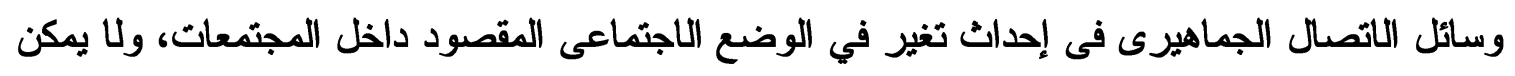

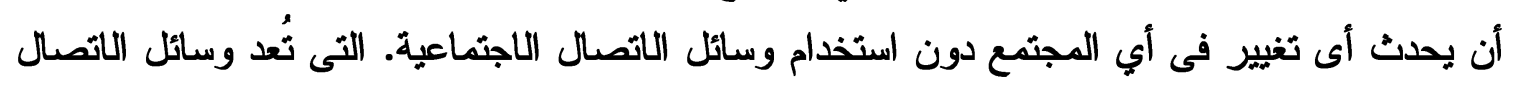

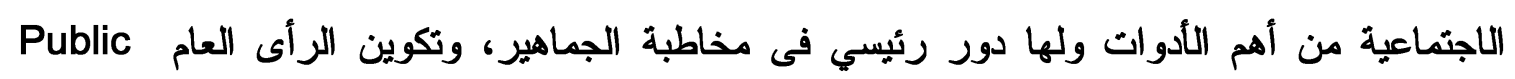

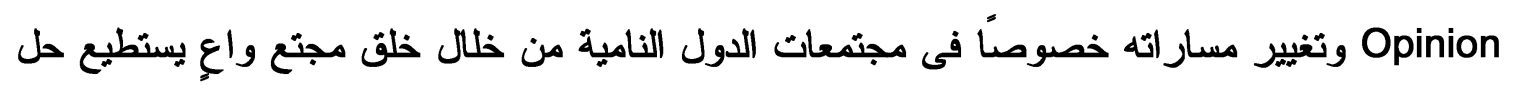

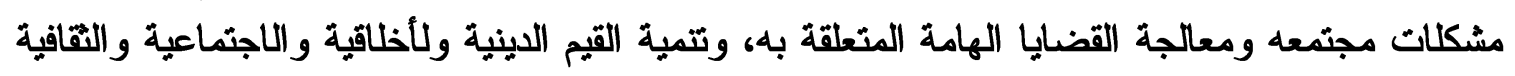
والقومية، والجمالية، كما تُمثل وسائل الاتصال الاجتماعى المحور الأساسى لنشر الثقافة وترسيخ مكونات التهات

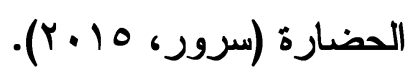
من هنا جاءت هذه الدراسة للتعرف على أثر وسائل التواصل المختلفة على منظومة القيم. 


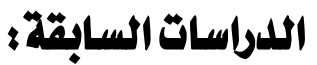

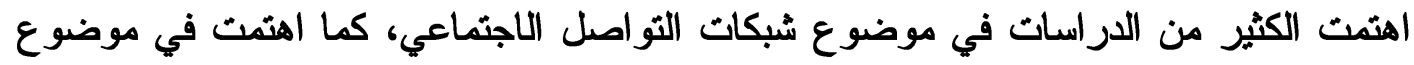

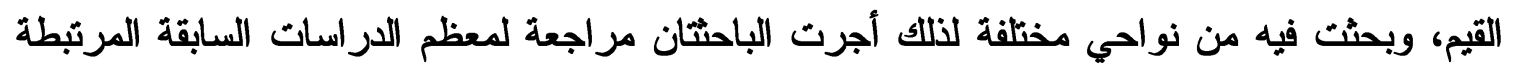

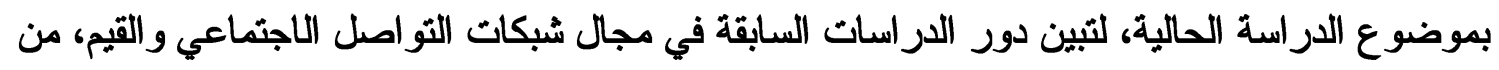

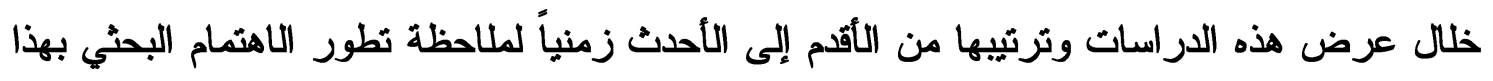

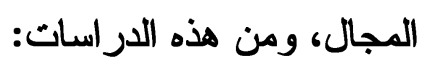

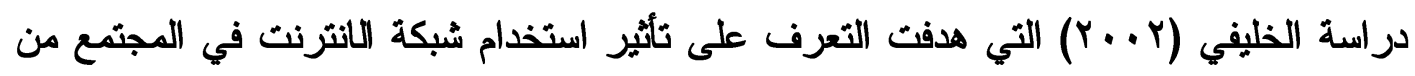

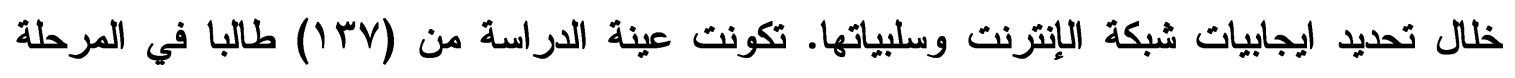

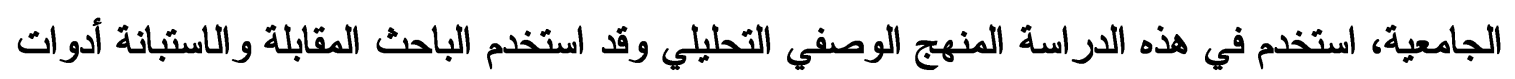

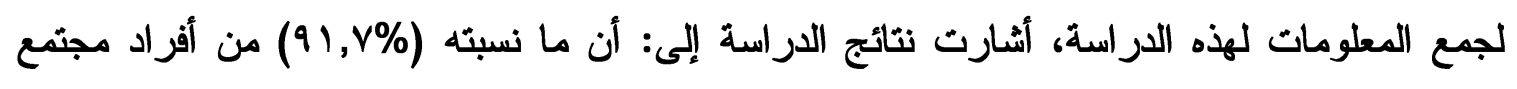

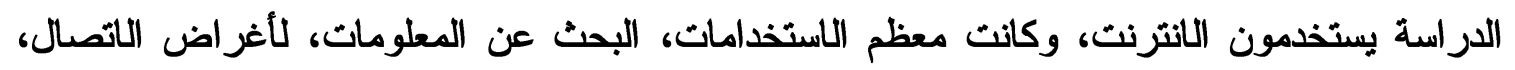

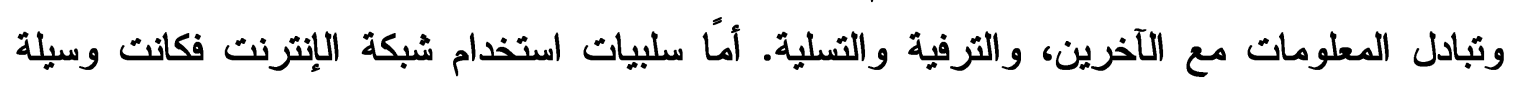
للغزو الثقافي، وسبب في الكثير من المشاكل الاجتماعية والأخلآية، والصحية.

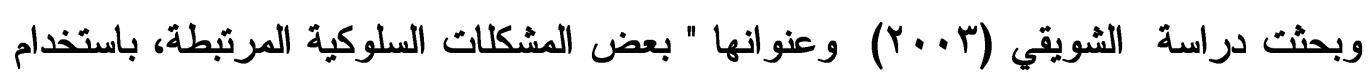

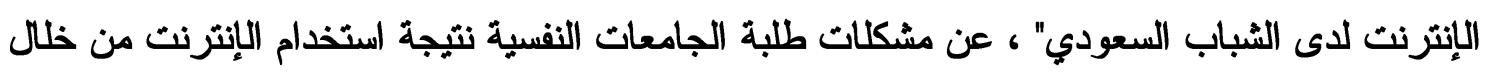

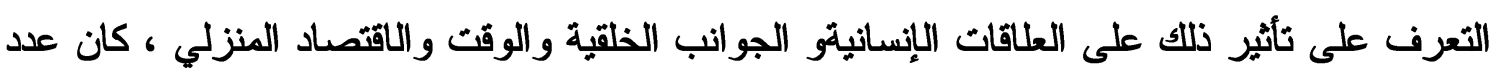

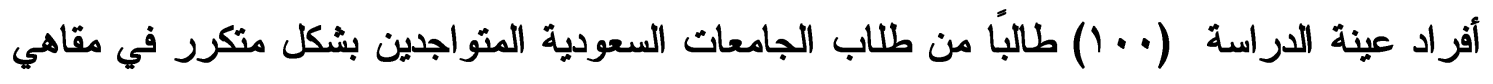

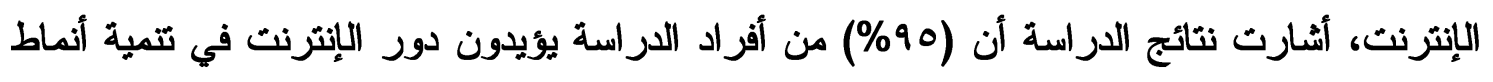

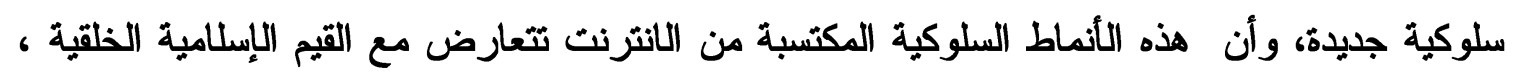

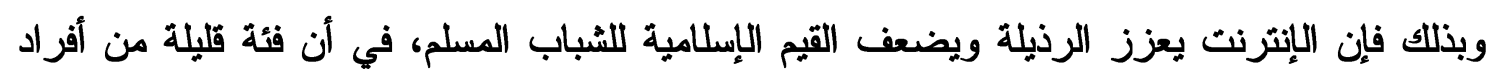

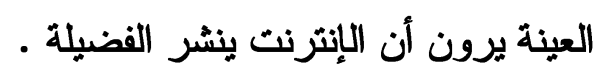

كذلك هدفت دراسة كل من أبو عيطة، والمشهاني (2004) معرفة العاقة بين القيم والاتجاهات

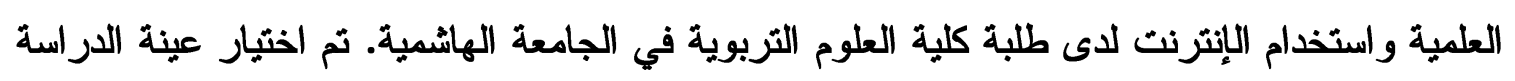

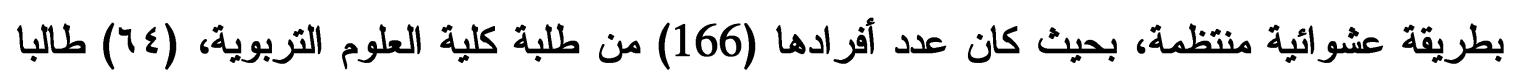

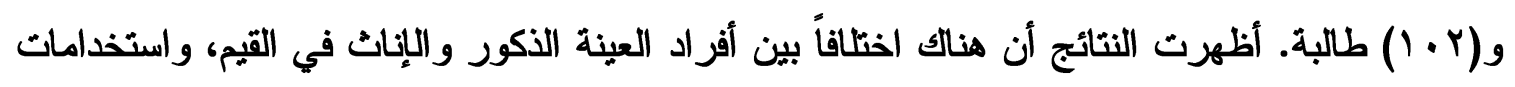

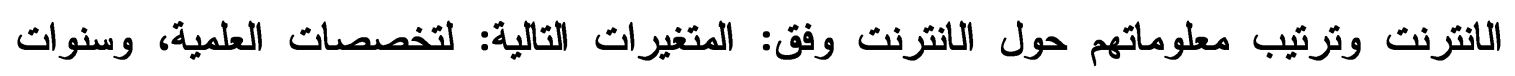


الدراسية، كماأشارث النتائج أن هناك علاقة ارتباط دالة بين الاتجاهات العلمية والقيم الوسيلية من جهة، وبين لقيم الوسيلية ومعلومات الطلبة حول الإنترنت واستخداماتهم له من جهة أخرى.

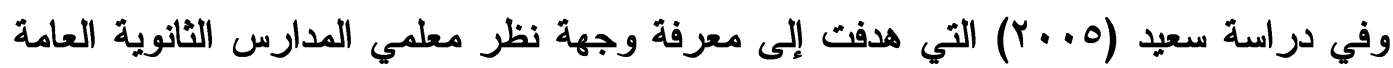

بمنطقة الباحة، حول الآثار الإيجابية والسلبية لوسائل العولمة على القيم الخلقية في المدارس الثانوية بالمملكة العربية السعودية، تم اختيار عينة عشوائية معتمدة على التوزيع الجغرافي للمنطقة من

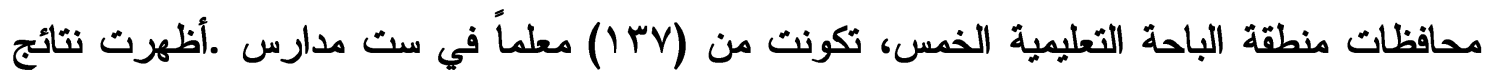

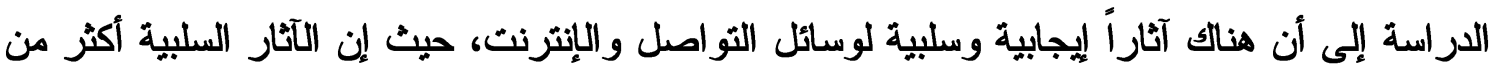

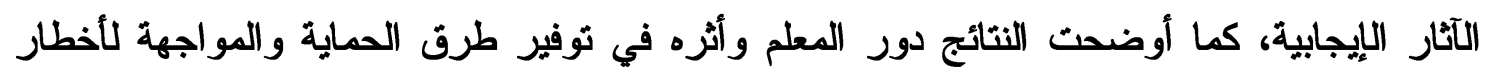
العولمة على المتعلمين بالمدرسة الثانوية بالمملكة العربية السعودية.

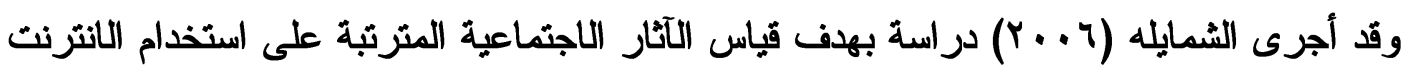

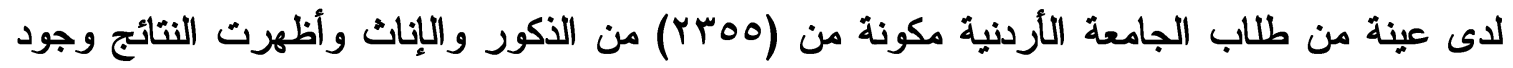
تأثير سلبي منذفض لاستخدام الانترنت على العادات والثقاليد والمعتقدات الدينية، وان التأثير كان سلبيا بدرجة منوسطة في المجال النفسي والأخلاقي، وكان الثأثير ايجابيا في المجال الثقافي والعلمي.

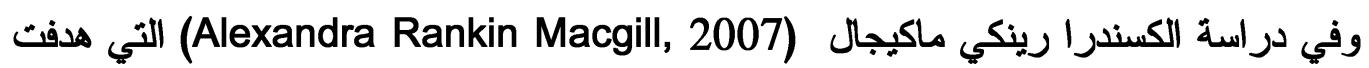
التعرف على مدى استخدام الآباء والمراهقين الأمريكيين شبكات التواصل ، كما هدفت التعرف على

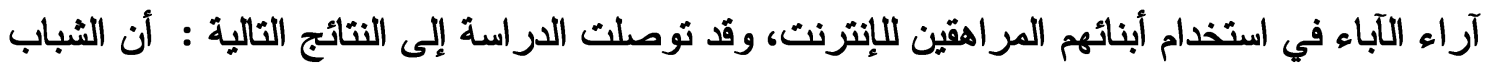

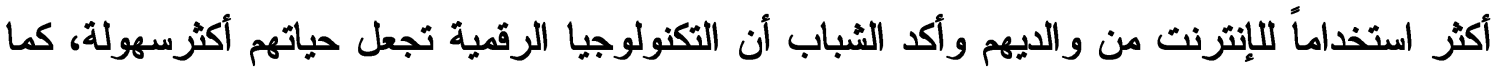

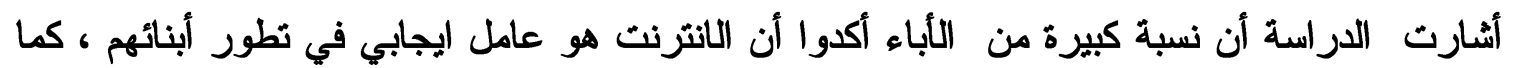

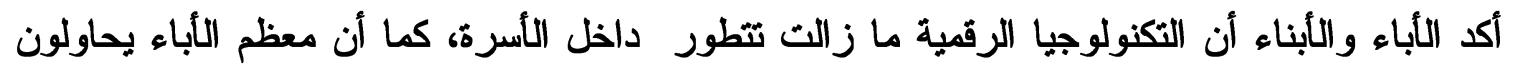

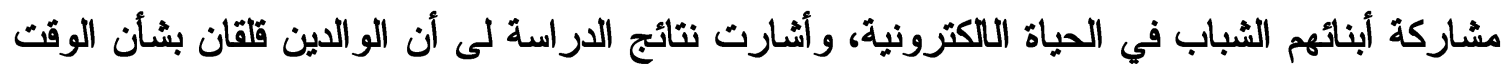

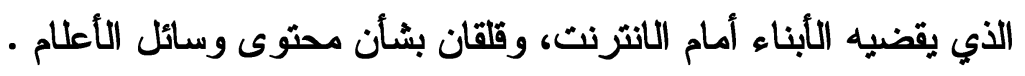

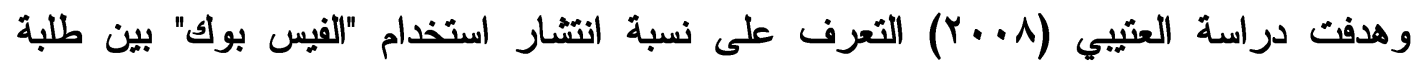

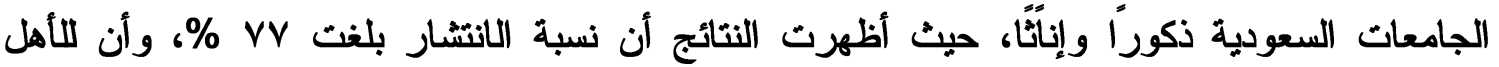
والأصدقاء دور وأثر كبير على طلبة الجامعات لاستخدام الفيس بوك بهدف تمضية الوقت، واعتبر هذات التهات الدور العامل الرئيس الذي دفع طلبة الجامعات السعودية لاستخدامه، كما أثارت النتائج أن نأثير الفيس بوك على شخصية الطلبة أكثر من أثر الوسائل الإعلامية الأخرى. 
كما قام الباحثان (Sameer Hinduja) من جامعة (Justin Patchin) و (Jlorida Atlantic)

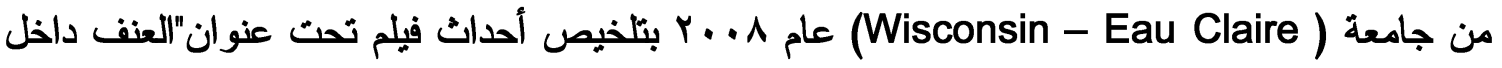
فناء المدارس "بهدف الحد من هذا العنف وقاما بتأليف كتاب عن جرائم عبر الانترنت، بعد أن تزايدت نسبة العنف في السنوات الأخيرة بمدارس الولايات المتحدة ، واحتوى الكتاب نتائج الفيلم باستطلاع آراء

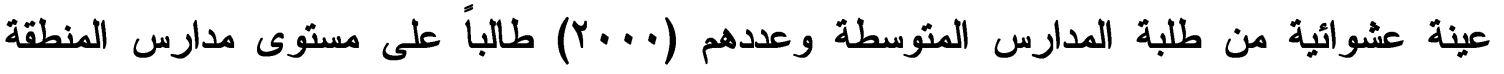

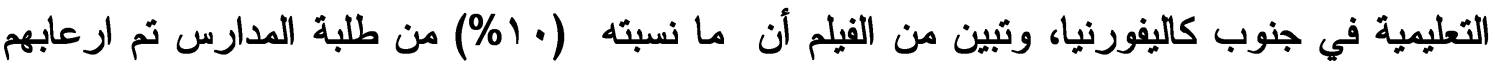

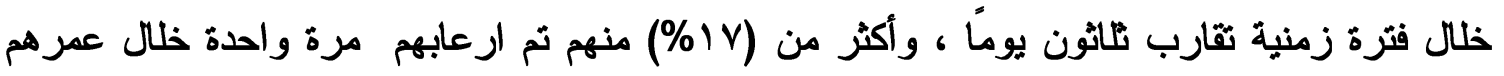

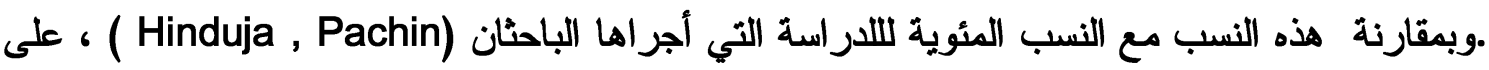
المراهقين الأكبر سناً ،بينت نتائجها أن نسب الطلبة المراهقين كانت أعلى، أي أن عدد الطلبة الذين يستخدمون الانترنت ويتقاعلون مع جرائم الانترنت أكثر من عدد الطلبة المراهقين الأقل منهم سناً. وفي استطلاع الرأي مع بعض المختصين حول حماية الأبناء من أخطار مواقع التواصل

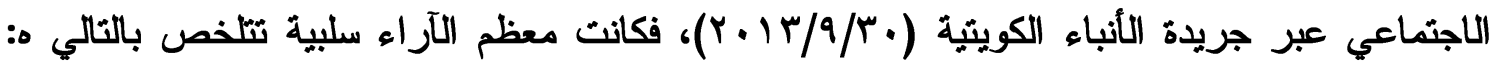
عزلة الأبناء اجتماعيا، وتوقفه عن ممارسة الأنشطة الرياضية والاجتماعية، وتأثر هم بأفكار واكتسابهم قيم جديدة مخالفة لقيم مجتمعاتهم ومخالفة لتعاليم الدين الحنيف، وزيادة نسبة العنف والعدوان في نفوسهم وضعف التحصيل في بعض المواد الأكاديمية.

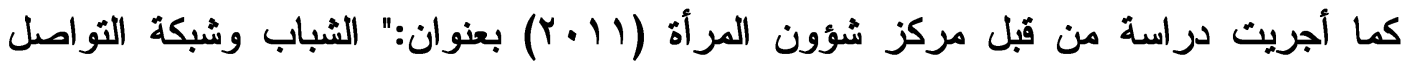
الاجتماعي". تكونت عينة الدراسة من شباب وشابات قطاع غزة في كافة القطاعات الخاصة والمؤسسات الحكومية. بينت نتائج الدراسة أن: مستخدمي شبكات التواصل الاجتماعي لا يستخدمون أسماءهم الحقيقية بل يستخدمون أسماء مستعارةهوكانت أهم أدوات التواصل الاجتماعي المستخدمة هي على التواتي: لئي: البريد الالكتروني، محركات البحث، الفيس بوك، وأن غالبية مستخدمي شبكات التواصل التهل الاجتماعي لايهم

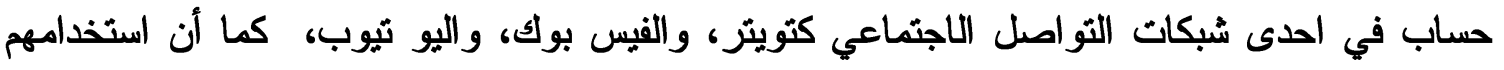
لشبكات التواصل كان منذ أكثر من من عامين، وأن من أسباب استخدام وسائل التواصل هي: تتمية المهارات المختلفة، تعزيز الذات، التنفيس عن الانفعاكات المكبوتة، الرغبة في التعبير عن وجهة النظر بحرية، ، التواصل وإنشاء الصداقات، التعبير عن المشاعر.

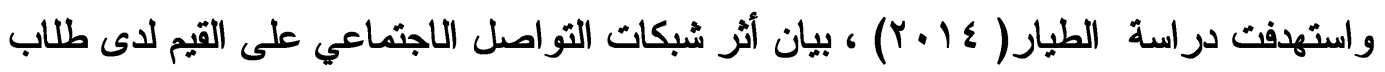
الجامعة ، بيان كل من الآثار السلبية والآثار الإيجابية المترتبة على استخدام طلاب الجامعة لشبكات

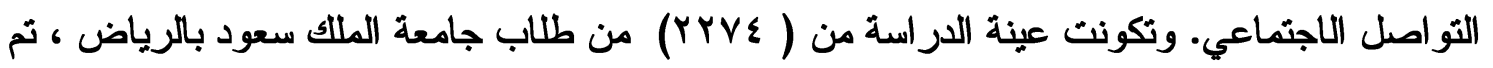


اختيارهم بطريقة عشوائية .أشارت نتائج الدراسة :أن أهم الآثار السلبية لشبكات التواصل: التمكن من

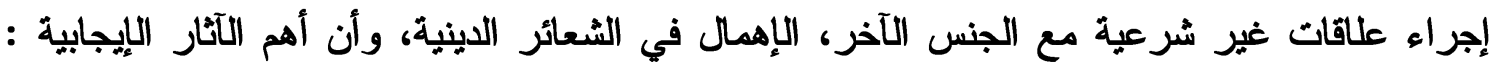

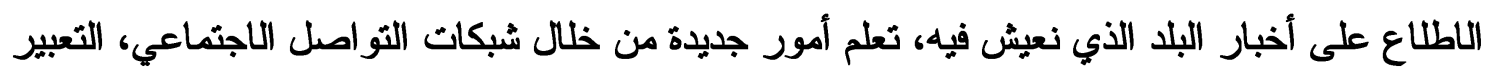
بحرية عن الرأي، التمكين من تخطي حاجز الخجل، وأن أهم مظاهر تغيير القيم نتيجة شبكات التواصل ظهر في :تعزيز استخدام الطالب لشبكات التو اصل الاجتماعي، القدرة على مخاطبة الجنس الآخر بجرأة.

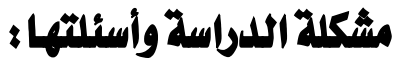

بحكم تخصصنا في علم النفس والعلوم التربوية ( التربية الخاصة ، والقياس والثقويم ) ، فإن القيم ومكونات الشخصية تعتبر العنصر الأساسي في أي تخصص علمي لاسيما علم النفس، كذللك فإن مساهمتا كباحثين منصلين بما يجري من تغيرات في المؤسسات التعليمبة كالجامعات وغيرهات فئما من دور العلم لا بد من المساهمة الفعلية في التراكم المعرفي حول موضوع القيم ووسائل التو اصل الاجتماعي من

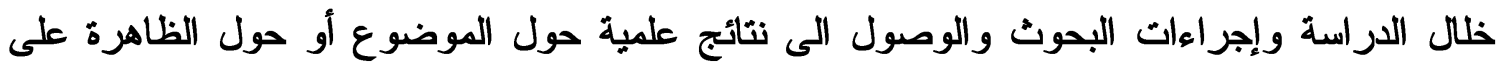
عينة من الدراسة لم يسبق أن أجري عليها مثل هذه الدراسات خاصة أن جامعة عمان الأهلية ممثلة بطلبتها وإدارتها وكوادرها وكل المنتسبين إليها تعتبر من أهم الجامعات التي تغذي سوق العمل بخريجيها، ولها هيبة وسمعة على المستوى المحلي والعالمي •

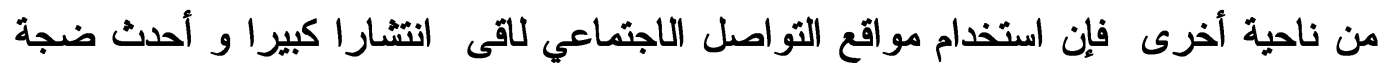

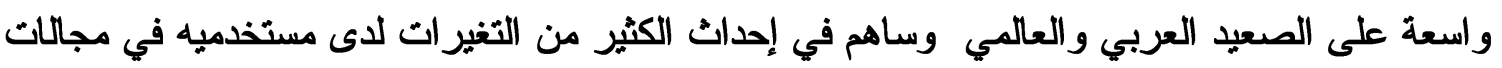

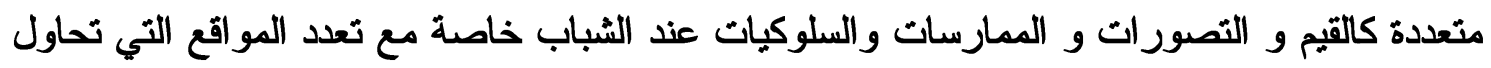
إنباع فضول الشباب.

ومن هنا جاءت هذه الدراسة الثي تتناول معرفة أثر مواقع التواصل الاجتماعي على القيم، لتجيب

$$
\text { عن أسئلة الدراسة الآتية: }
$$

ا.ما هو أثر شبكات التواصل الاجتماعي على القيم الاجتماعية لدى طلبة جامعة عمان الأهلية؟

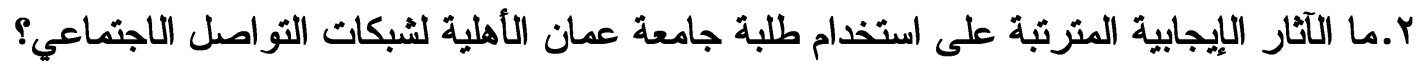

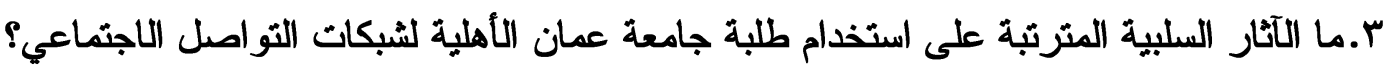
ع. هل توجد فروق دالة احصائيًا عند مستوى دلالة (a في تغيير القيم الاجتماعية لدى طلبة جامعة عمان الأهلية تعزى للمتغيرات الديمغر افية التالية:

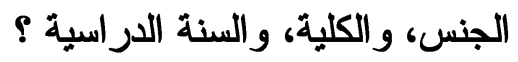




\section{أهداث الدراسة}

• بيان تأثير استخدام شبكات التواصل الاجتماعي على القيم الاجتماعية لدى طلبة جامعة عمان

الأهلية.

• بيان الآثار الإيجابية المترتبة على استخدام طلبة جامعة عمان الأهلية لشبكات التواصل

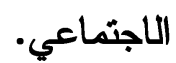

• بيان الآثار السلبية المثرثبة على استخدام طلبة جامعة عمان الأهلية لشبكات التواصل

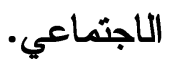

\section{أهية الدراسة}

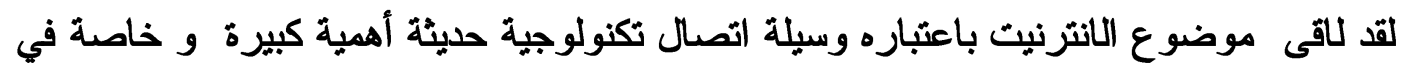

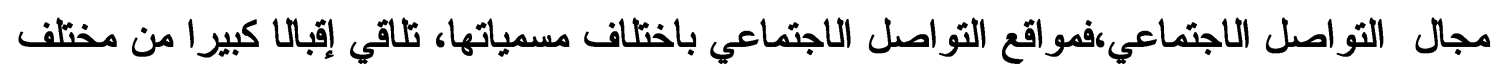

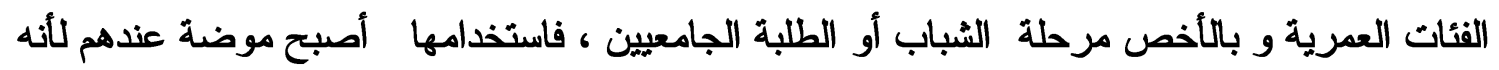

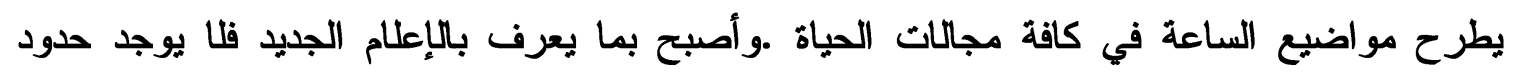

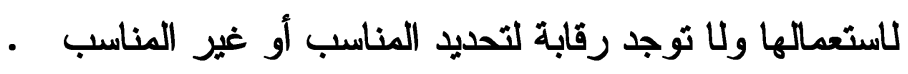
من هنا يمكن بيان أهمية الدراسة في ضوء الماء الاعتبارات التالية:

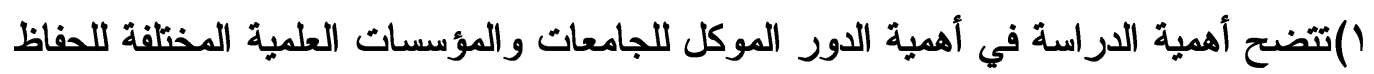

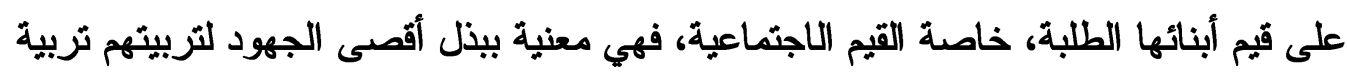

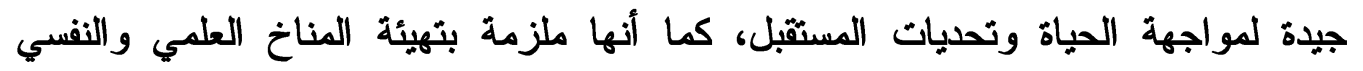

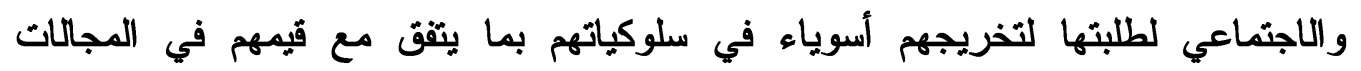

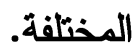

r)يمكن الاستفادة من نتائج هذه الدراسة في توعية أولياء أمور الطلبة بالآثار السلبية لشبكات

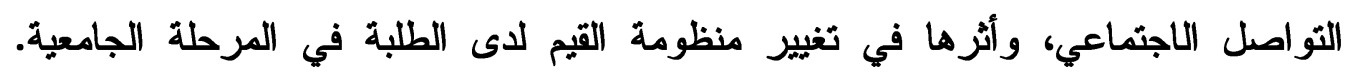
وكيف ينبغي لهم أن ينعرفوا على هذه التقنية حتى يمكنهم مراقبة أبنائهم . 
ץ)يمكن أن تساعد هذه الدراسة متخذي القرار في وسائل الإعلام، و المؤسسات الجامعية المختلفة بما فيها جامعة عمان الأهلية بأهمية مرحلة الشباب، وكيفية إكسابهم منظومة قيم تمثاز بالقوة و الثبات ومواجهة التحديات، وأن تتماشى وأخلاقيات دينتا الحنيف. ع)توعية الطلبة بأهمية شبكات التواصل الاجتماعي لاكتساب ما هو مفيد والابتعاد عما هو رديء، وبيان أثز ذلك على قيمهم خاصة في هذه المرحلة العمرية في سن المرحلة

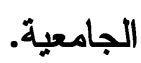

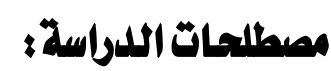

مواقع التواصل الاجتماعي، منظومة القيم الاجتماعية، طلبة جامعة عمان الأهلية مواقع التواصل الاجنماعي:

"مجموعة منظمة من الشبكات الإكثرونيّة يشترك فيها مجموعة من الأفراد أو المؤسسات بإنشاء موقع خاص بكل منهم، ومن ثم ربطه عن طريق نظام اجتماعي إلكتروني مع أعضاء آخرين لديهم

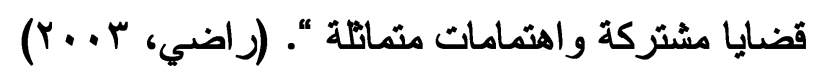
التعريف النظري للقيم (values):

رغم اختلاف المنظرين من رجال العلم ، مفكرين وفلاسفة وتربويين عبر العصور الماضية، الا انها مجموعة من التصورات والمعثقدات الوجدانيةو المعرفية ثقوم عليها عملية التقاعل الاجتماعي والتي تحدد المرغوب وتقوم الأفراد وتحدد سلوكهم وثقاقتهم واهتماماتهم ومظاهرهم، يختارها الأفراد

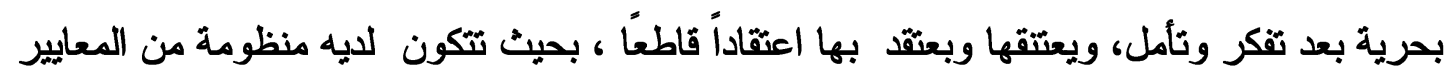
يحكم بها على السلوكات والأشياء بالقبول أو الرفض، بالايجابي أو السلبي، وتتميز السلوكات

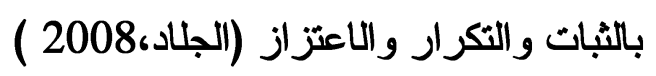
طلبة جامعة عمان الأهلية: مجموعة الطلاب و الطالبات المسجلين ويتلقون تعليمهم في جامعة عمان الأهلية.

\section{حدود الداسبة}

الحدود الموضوعية: 
تقتصر حدود الدراسة الحالية على دراسة أثر مواقع التواصل الاجتماعي في منظومة القيم الاجتماعية دى طلبة جامعة عمان الأهلية. الحدود المكانية (البعد المكاني):

تقتصر حدود الدراسة لحالية على الطلبة المسجلين في جامعة عمان الأهلية ويدرسون فيها.

$$
\text { الحدود الزمنية (البعد الزماني): }
$$

تقتصر حدود الدراسة الحالية على الطلبة الذين يدرسون في جامعة عمان الأهلية في العام

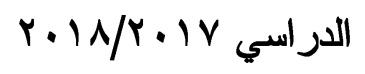

\section{المنهج والإجراءات Methods \\ منرج الدراسة}

تم استخدام المنهج الوصفي التحليلي للتوصل إلى أثر مواقع التواصل الاجتماعي في منظومة القيم الاجتماعية لدى طلبة جامعة عمان الأهلية.

تكون مجتمع الدراسة من طلاب جامعة عمان الأهلية، المسلين في العام الدراسي

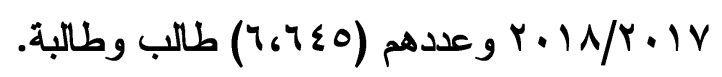

\section{مينة الدراسة:}

تكونت عينة الدراسة من 100 طالبا وطالبة من طلاب جامعة عمان الأهلية المسجلين في

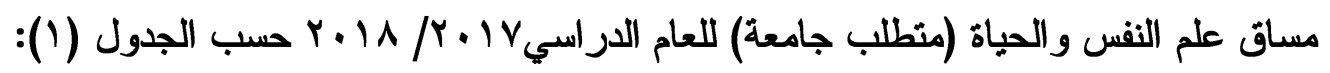

\begin{tabular}{|c|c|c|c|}
\hline النسبة \% & التكرار & الفئات & المتغير \\
\hline 56.0 & 56 & ذكر & \multirow[t]{2}{*}{ الجنس } \\
\hline 44.0 & 44 & انثى & \\
\hline 59.0 & 59 & علمية & \multirow[t]{2}{*}{ الكلية } \\
\hline 41.0 & 41 & إنسانية & \\
\hline 19.0 & 19 & أولى & السنة \\
\hline
\end{tabular}

جدول (1)

النكرارات و النسب المئوية حسب منغير ات الدراسة 


\begin{tabular}{|c|c|c|}
\hline 22.0 & 22 & ثانية \\
\hline 28.0 & 28 & ثالثة \\
\hline 31.0 & 31 & رابعة فأكثر \\
\hline
\end{tabular}

\section{أداة الدراسة}

لجمع المعلومات اللازمة المتعلقة بهده الدراسة قامت الباحثثان بتصميم استبانة بعد الرجوع الى أدب الموضوع و الدر اسات السابقة، وتكونت الاستبانة من قسمين:

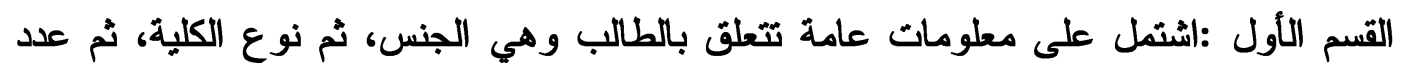
سنوات الدراسة التي أتمها بالجامعة، ثم الجنسية والمعدل التراكمي للطالب.

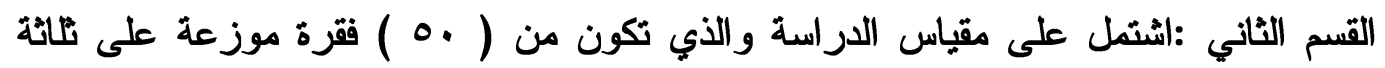

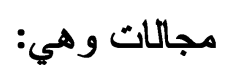

المجال الأول :ويقيس أثر شبكات التواصل الاجتماعي في تغيير القيم الاجتماعية لدى طلبة جامعة

$$
\text { عمان الأهلية ، ويشمل (•r) فقرة. }
$$

المجال الثاني: ويقيس الآثار الإيجابية الناتجة عن استخدام مواقع التواصل الاجتماعي، ويشمل

$$
\text { (10) }
$$

المجال الثالث: ويقيس الآثار السلبية الناتجة عن استخدام شبكات الثواصل الاجتماعي،، ويشمل

$$
\text { (10) }
$$


وقد صُممت الاستجابة على أداة الدراسة، وفق مقياس ليكرت Lekert الخماسي، كما يلي: - أو افق بدرجة كبيرة جداً (0) درجات. - أو افق بدرجة كبيرة (ع) درجات. • أو افق بدرجة متوسطة (؟ّ) درجات. - أو افق بدرجة ضعيفة (درجتان). - أو افق بدرجة ضعيفة جداً (درجة واحدة) أورجة) المعيار الإحصائي في تصحيح الأداة: لأغراض تهأ تفسير المتوسط الحسابي لإجابات أفراد العينة،

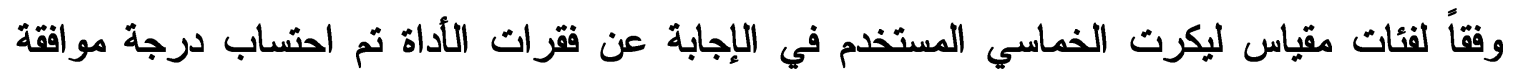
الطلبة على فقرات المقياس وفق معادلة المدى، حيث تم تحديد طول الفئة وفقاً للمعادلة الآتية:

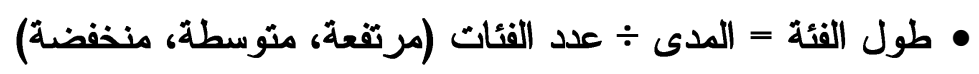
• المدى = أكبر قيمة لفئات الإجابة - أصغر قيمة لفئات الإجابة

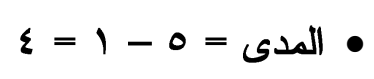

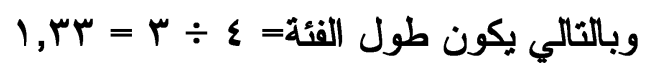
وهكذا تصبح الأوزان على النحو الآتي:

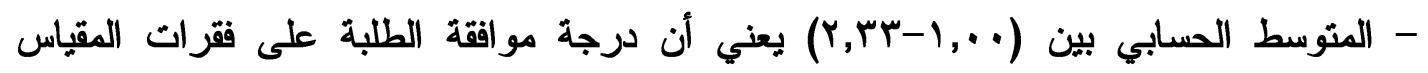
منخفضة. - المتوسط الحسابي بين (ع r,Yمنوسطة.

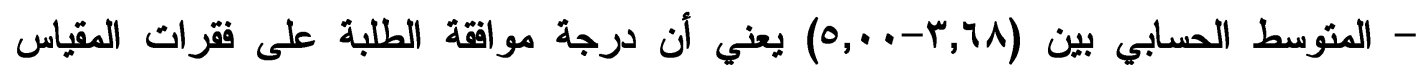
مرتفعة.

\section{صلدق البناء:}

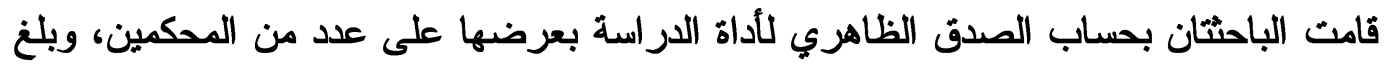

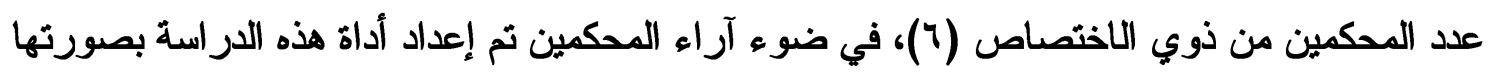
النهائية. ولاستخراج دلآات صدق البناء للأداة، استخرجت معاملات ارتباط فقرات المقياس مع الدرجة

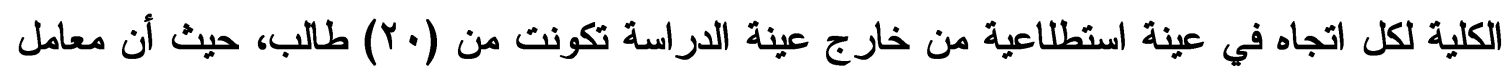


الارتباط هنا يمثل دلالة للصدق بالنسبة لكل فقرة في صورة معامل ارتباط بين كل فقرة وبين الدرجة الكلية للمجال التي تنتمي اليه، وقد تراوحت معاملات ارتباط الفقرات مع الدرجة الكلية لمجال القيم

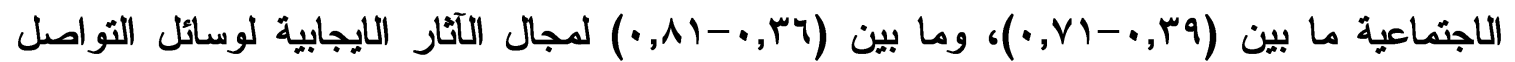

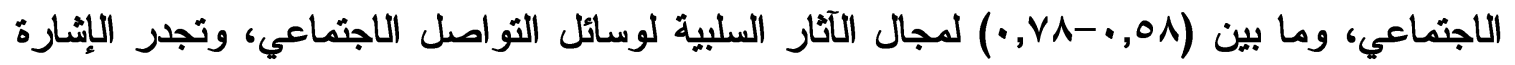

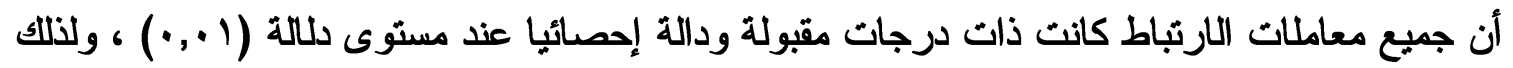
لم يتم حذف أب من هذه الفقرات، مما يدل على ملاءمة الاستبانة للتطبيق لغايات الدراسة. والجدول (r) يوضح ذلك.

جدول (Y)

معاملات الارتباط بين الفقرات و الدرجة الكلية للمجال التي تثنمي اليه

\begin{tabular}{|c|c|c|c|c|c|}
\hline لوسائل التواصثار السلبية & رقم & لوسائل التواصل الايجابية & رقم الفقرة & الاجتماعية & رقم الفقرة \\
\hline$* * 66$ & 36 & $* .38$ & 21 & $* * .51$ & 1 \\
\hline$* * 67$ & 37 & $* 42$ & 22 & $* 39$ & 2 \\
\hline$* * .58$ & 38 & $* * 66$ & 23 & $* * .58$ & 3 \\
\hline$* * .66$ & 39 & $* * .59$ & 24 & $* * .66$ & 4 \\
\hline$* * .58$ & 40 & $* .44$ & 25 & $* * .47$ & 5 \\
\hline$* * .72$ & 41 & $* .36$ & 26 & $* * .68$ & 6 \\
\hline$* .72$ & 42 & $* * 49$ & 27 & $* * .49$ & 7 \\
\hline$* * .61$ & 43 & $* * .70$ & 28 & $* * .63$ & 8 \\
\hline$* * .64$ & 44 & $* * .74$ & 29 & $* * 61$ & 9 \\
\hline$* * .65$ & 45 & $* * .81$ & 30 & $* * .63$ & 10 \\
\hline$* * .78$ & 46 & $* * .75$ & 31 & $* * .62$ & 11 \\
\hline$* * .67$ & 47 & $* * .70$ & 32 & $* * 69$ & 12 \\
\hline$* * .66$ & 48 & $* * 69$ & 33 & $* * .65$ & 13 \\
\hline$* * .65$ & 49 & $* * .52$ & 34 & $* * .65$ & 14 \\
\hline \multirow[t]{5}{*}{$* * .58$} & 50 & $* * .62$ & 35 & $* * .71$ & 15 \\
\hline & & & & $* * .67$ & 16 \\
\hline & & & & $* .42$ & 17 \\
\hline & & & & $* * .71$ & 18 \\
\hline & & & & $* * .55$ & 19 \\
\hline
\end{tabular}




\begin{tabular}{|c|c|c|c|c|c|}
\hline لوسائل التّار السلبية & رقم & لوسائل التار الايجابية & رقم الفقرة & الاجثماعية & رقم الفقرة \\
\hline & & & & $* .64$ & 20 \\
\hline
\end{tabular}

\section{ثبات أداةالدراسة:}

تم التحقق من ثبات أداة الدراسة، بطريقة الاختبار وإعادة الاختبــار (test-retest) بتطبيــق

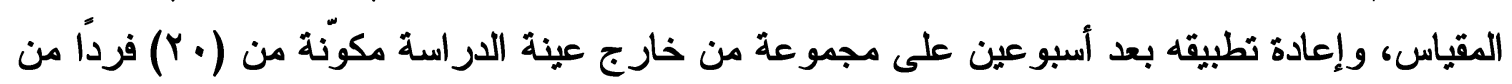
طلبة جامعة عمان الأهلية، ومن ثم تم حساب معامل ارثباط بيرسون بين ثقديرات الطلبة في المرتين، كما ثم أحساب معامل الثبات بطريقة الاتساق الداخلي حسب معادلة كرونباخ ألفا، و الجدول رقم (ب) يبين معامل الاتساق الداخلي وفق معادلة كرونباخ ألفا وثبات الإعادة للمجالات والأداة ككل واعثبرت هذه القيم ملائمة لغايات هذه الدر اسة.

جدول (r)

معامل الاتساق الداخلي كرونباخ ألفا وثبات الإعادة للمجالات و الدرجة الكلية

\begin{tabular}{|c|c|c|}
\hline الاتساق الداخلي & ثبات الإعادة & 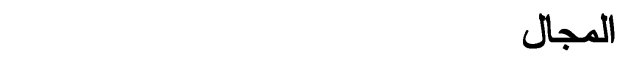 \\
\hline 0.84 & $\cdot, \wedge \vee$ & القيح الاحتماعية \\
\hline 0.83 & $\cdot, 9$. & الآثار الايجابية لوسائل التو اصل الاجتماعى \\
\hline 0.90 & $\cdot 9 r$ & الآثار السلبية لوسائل التو اصل الاجتماعى \\
\hline
\end{tabular}




\section{النتائج ومنالأشتها:}

\section{السؤال الاول: ما أثر استخدام طلبة جامعة عمان الأهلية لشبكات التواصل الاجتمامي في

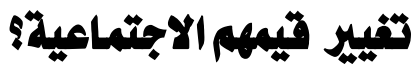

للإجابة عن السؤال تم حساب المتوسطات الحسابية والانحرافات المعيارية لاستخدام شبكات التواصل الاجتماعي في تغيير القيم الاجتماعية لدى طلبة جامعة عمان الأهلية، والجدول (ع) أدناه ييين لك.

جدول (乏)

المتوسطات الحسابية والانحر افات المعيارية لاستخدام شبكات التواصل في تغيير القيم الاجتماعية لدى

طلبة جامعة عمان الأهلية مرتبة تنازلياً حسب المتوسطات الحسابية

\begin{tabular}{|c|c|c|c|c|c|}
\hline الدرجة & الانحر اف & المتوسط & الفقرات & 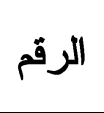 & الرتبة \\
\hline كبيرة & .714 & 4.57 & أحتر م كبار السن وأساعدهم & ir & 1 \\
\hline 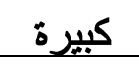 & .740 & 4.41 & أتو اضع فى تعاملى مع الأخرين & $r$ & r \\
\hline 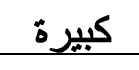 & .884 & 4.37 & أعامل جير انى بصورة حسنة & 1 & $r$ \\
\hline كبيرة & .914 & 4.35 & أسر ع لمساعدة الجيران عند طلب المساعدة & $\Lambda$ & $\varepsilon$ \\
\hline كبيرة & .809 & 4.35 & أقدم العون و المساعدة للآخرين عند الحاجة & iv & $\varepsilon$ \\
\hline كبيرة & .867 & 4.34 & أحرص على تكوين علاقات اجتماعية مع & r & 7 \\
\hline كبيرة & .913 & 4.29 & أستمع الى حديث الآخرين بأدب & 0 & $\checkmark$ \\
\hline 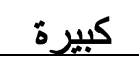 & .911 & 4.24 & أحرص على عدم إز عاج جير انى. & 7 & $\Lambda$ \\
\hline 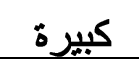 & .952 & 4.23 & أقدر قيمة المساواة بين الجنسين فى التعامل & 10 & 9 \\
\hline كبيرة & .924 & 4.21 & أقول الحق مهما كانت النتيجة & $\checkmark$ & 1. \\
\hline كبيرة & .964 & 4.20 & أتنازل عن بعض مطالبى إرضاءً لو الدي. & ir & 11 \\
\hline كبيرة & .950 & 4.19 & أشارك الناس أفراحهم وأتراحهم & 9 & ir \\
\hline كبيرة & 1.000 & 4.10 & أتقبل آراء الآخرين وأناقشهم بوضوعية & 11 & ir \\
\hline 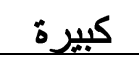 & .986 & 4.09 & أتجنب تجريح الآخرين وسوء الظن بهر & 19 & $1 \varepsilon$ \\
\hline كبيرة & 1.245 & 3.81 & أساعد أسرتى بالأعمال المنزلبة. & r. & 10 \\
\hline كبيرة & 1.219 & 3.78 & أحب المشاركة في مصروفات الأسرة & 17 & 17 \\
\hline متوسطة & 1.129 & 3.67 & أتخذ قرار اتى بعد استشارة الآخرين. & 11 & iv \\
\hline متوسطة & 1.209 & 3.56 & أهتم بالبر امج ذات الطابع الاجتماعى. & 1. & 11 \\
\hline متوسطة & 1.185 & 3.47 & أستثر وقت فراغى بما بعود بالنفع على & $1 \varepsilon$ & 19 \\
\hline
\end{tabular}




\begin{tabular}{|c|c|c|c|c|c|}
\hline الدرجة & الانحر اف & المتوسط & الفقرات & 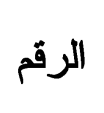 & 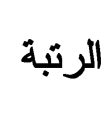 \\
\hline ؤسطة & 1.262 & 3.39 & أساهم في الأعمال التطوعية دومًا. & $\varepsilon$ & $r$ r. \\
\hline كبيرة & .471 & 4.08 & القيم الاجتماعية & & \\
\hline
\end{tabular}

يبين الجدول (ع) ان المتوسطات الحسابية تراوحت مابين (3.39-4.57)، حيث جاءت الفقرة

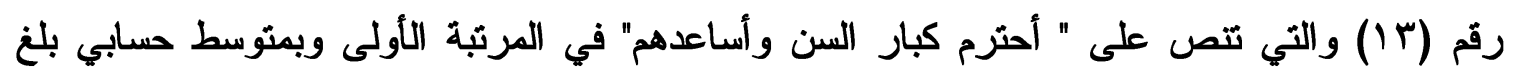
(4.57)، بينما جاءت الفقرة رقم (ع) ونصها "أساهم في الأعمال التطوعية دومًا" بالمرنبة الأخيرة

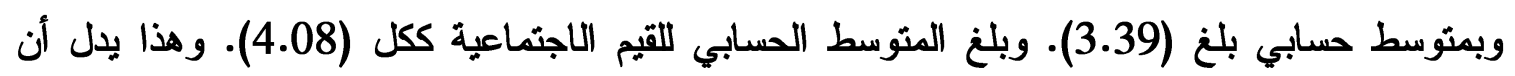

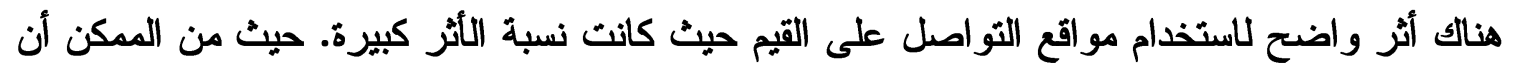

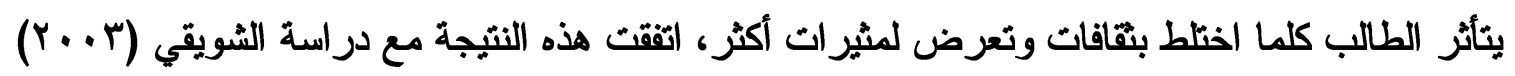
التي أظهرت نتائجها أن ما تسبته 90\% من أفراد الدراسة يرون دور الإنترنت في تتمية أنماط سلوكية

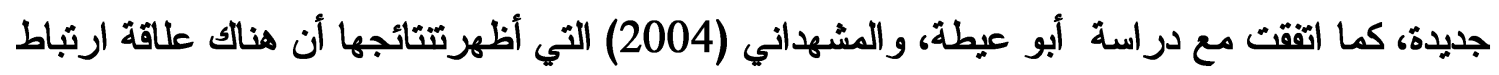

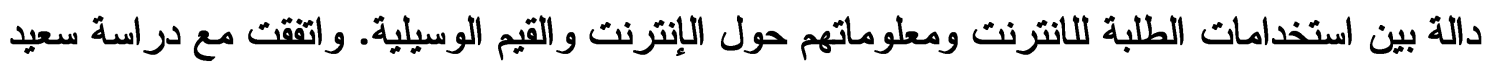

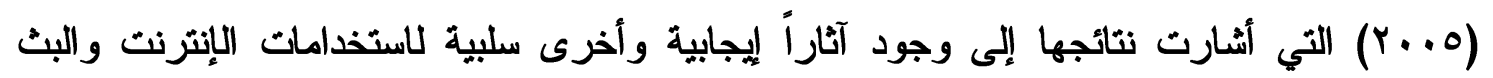

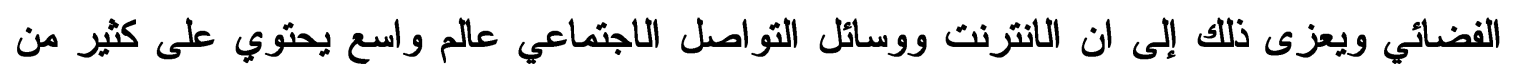
الأشياء المفيدة والمسلية وكذلك الضارة، وقد تعتمد على مدى الوعي الذي يمتلكه مستخدمي هذه الوسائل

\section{السؤال الثاني: ما الآثار الإيجابية المترتبة على استخدام طلبة جامعة عمان الأهلية ثشبكات}

\section{التواصل الاجتماهي:}

للإجابة عن هذا السؤال تم استخراج المتوسطات الحسابية والانحرافات المعيارية للآتار الإيجابية المترنبة على استخدام طلبة جامعة عمان الأهلية لشبكات التو اصل الاجتماعي، والجدول (ه) أدناه يوضح ذلك.

$$
\text { جدول (0) }
$$

المتوسطات العسابية والانحر افات المعيارية للآثار الإيجابية المترتبة على استخدام طلبة جامعة عمان

$$
\text { الأهلية لشبكات التو اصل الاجتماعي مرتبة تنازلياً حسب المتوسطات الحسابية }
$$




\begin{tabular}{|c|c|c|c|c|c|}
\hline 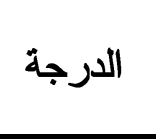 & 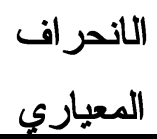 & المستوسط & الفقرات & 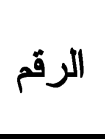 & 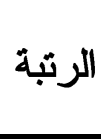 \\
\hline 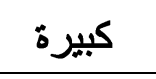 & 1.036 & 4.09 & تزودني بالأخبار المحلية والعالمية أولاً بأول & r) & 1 \\
\hline كبيرة & .952 & 4.06 & 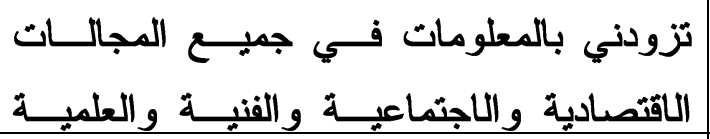 & rt & $r$ \\
\hline كبيرة & 1.049 & 4.01 & الأقارب و الأصداعد في مد حبال المــودة و التو اصــل مـــع & rᄉ & r \\
\hline كبيرة & 1.044 & 3.98 & تسهل علي العمل وتختصر الوقت والجهر & ז & $\varepsilon$ \\
\hline كبيرة & 1.022 & 3.92 & و المعلوماتي في صقل خبر اتي و اكتسابي المعرفة & r & 0 \\
\hline 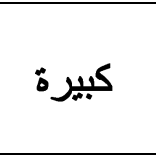 & 1.043 & 3.89 & المشاركين & r & 7 \\
\hline كبيرة & .879 & 3.88 & تساعدنى فى الوعى الصحى & rq & $\checkmark$ \\
\hline كبيزة & 1.195 & 3.84 & تسهل على متابعة أخبار المشاهير & ro & $\wedge$ \\
\hline كبيرة & 1.179 & 3.77 & تفتح أمامى سوق التجارة & $r \varepsilon$ & 9 \\
\hline 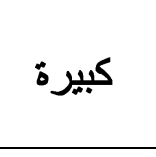 & 1.097 & 3.74 & 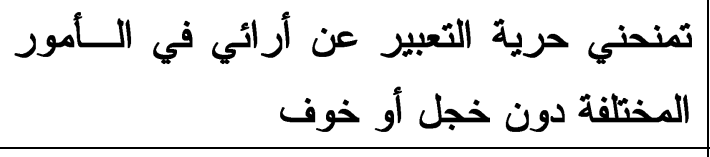 & rr & 1. \\
\hline كبيرة & 1.118 & 3.73 & تساعدنى فى تكوين صداقات جديدة & $r v$ & 11 \\
\hline كبيرة & 1.002 & 3.69 & تساعدنى فى الوعى الوطنى & r. & ir \\
\hline منوسطة & 1.063 & 3.61 & تساعدنى فى ترسيخ القيم الحميدة و المبــادئ & ro & ir \\
\hline متوسطة & 1.224 & 3.42 & تساعدنى فى تحسين مستوى التحصيل الدر اسى & rr & $1 \varepsilon$ \\
\hline متوسطة & 1.299 & 3.30 & تساعدنى فى الوعى الدينى & r & 10 \\
\hline كبيرة & .543 & 3.80 & الآثار الإيجابية لوسائل التواصل الاجتماع & & \\
\hline
\end{tabular}

يبين الجدول (ه) ان المتوسطات الحسابية قد تراوحت مابين (3.30-4.09)، حيث جاءت الفقرة

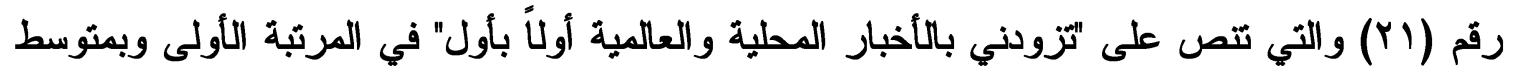
حسابي بلغ (4.09)، بينما جاءت الفقرة رقم (بr) ونصها "تساعدني في الوعي الديني" بالمرتبة الأخيرة

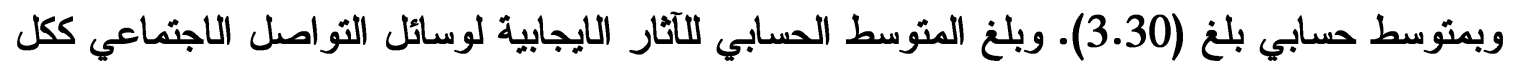

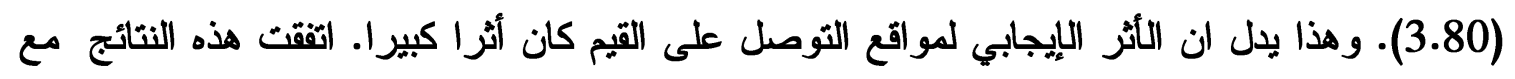




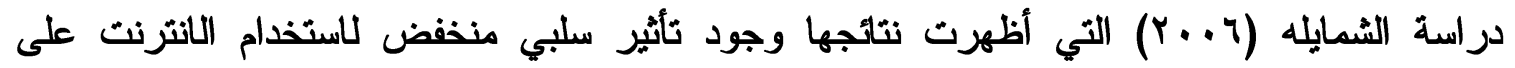

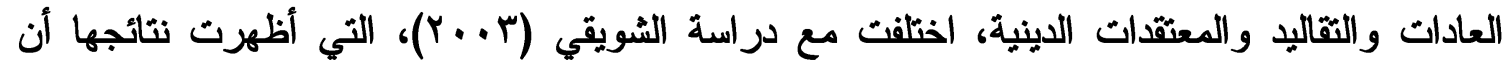
الأنماط السلوكية المكتسبة من استخدام وسائل التواصل الاجتماعي لاتتفق مع القيم الإبلامية والأخلاقية ،

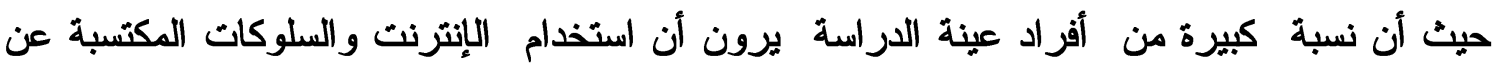
طريقه تعزز الرذيلة، كما يرون أن الإنترنت وسيلة حادة وفعالة لتدهور القيم الانسانية بشكل عام.

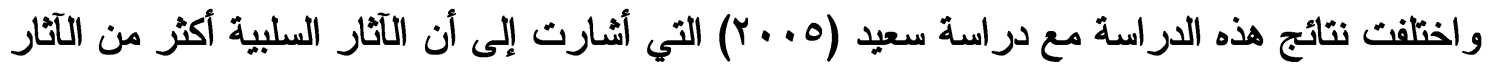

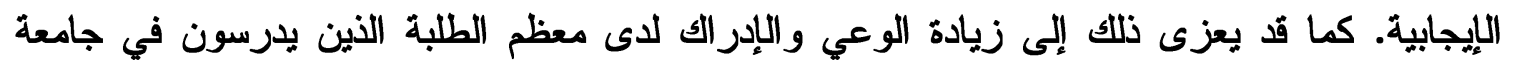

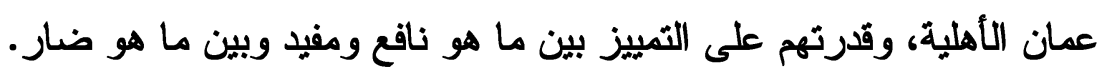

\section{السؤال الثالثة: ما الأثار السبية المترتبة على استخدام طلبة جامعة عمان الأهلية لشبكات}

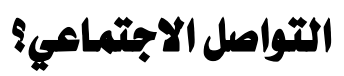

للإجابة عن هذا السؤال تم استخراج المتوسطات الحسابية والانحرافات المعيارية للآثار السلبية المترنبة على استخدام طلبة جامعة عمان الأهلية لشبكات التواصل الاجتماعي، والجدول (آ) أدناه يوضح

جدول (7)

المتوسطات الحسابية والانحر افات المعيارية للآثار السلبية المترتبة على استخدام طلبة جامعة عمان الأهلية لشبكات التواصل الاجتماعي مرتبة تنازلياً حسب المتوسطات الحسابية

\begin{tabular}{|c|c|c|c|c|c|}
\hline الدرجة & 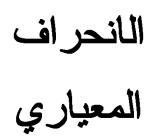 & المتوسط & الققر ات & 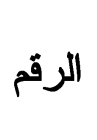 & 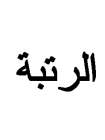 \\
\hline متو سطة & 1.410 & 3.52 & تتسبب في ضياعوقتى & $\varepsilon 0$ & 1 \\
\hline متوسطة & 1.266 & 3.29 & تشاعد في توسيع فجوة اختاف أرائي وآراء & $\varepsilon$. & r \\
\hline متوسطة & 1.413 & 3.27 & تساعد فى بعدى عن أفر اد أسرتى & $\varepsilon \varepsilon$ & r \\
\hline متوسطة & 1.553 & 3.18 & تآخراعد في إقامة علاقات غير شرعية مع الجنس & rq & $\varepsilon$ \\
\hline متوسطة & 1.349 & 3.17 & تساعد في تضليل المعلومات الدينية المنشورة & $\varepsilon r$ & ० \\
\hline
\end{tabular}




\begin{tabular}{|c|c|c|c|c|c|}
\hline الدرجة & المعياري - المراف & المسابي & الفقرات & 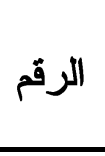 & الرتبة \\
\hline & & & على مواقع التو اصل & & \\
\hline متوسطة & 1.412 & 3.16 & تيؤدى الى عدم التركيز وتشتث الانتباه & $\varepsilon \wedge$ & 7 \\
\hline منوسطة & 1.433 & 3.13 & مثل تأخر الصلاة في الستهانة في أداء الواجبات الدينية & rv & $v$ \\
\hline متوسطة & 1.379 & 3.09 & تساعد في عزلتى وضعف تفاعلى الاجتماعى & rᄉ & $\Lambda$ \\
\hline متوسطة & 1.455 & 3.06 & تسبب لى عدم التوازن و البلبلة الفكرية & $\varepsilon \eta$ & 9 \\
\hline منوسطة & 1.377 & 2.94 & و الفيديوني خصوصبتي بنشر المعلومات و الصور & $\varepsilon \vee$ & 1. \\
\hline منوسطة & 1.319 & 2.91 & تساعد في زيادة النفقات و المصروفات على & $\varepsilon$ & 11 \\
\hline منوسطة & 1.364 & 2.91 & و تؤدي الى ضعف الانتماء للهوية الإسلامية & $\varepsilon r$ & 11 \\
\hline متوسطة & 1.399 & 2.89 & الواقع. تزيد لدي أحلام اليقظة و الهروب من مواجهة & $\varepsilon 9$ & ir \\
\hline منوسطة & 1.281 & 2.88 & و أفكاري اللغة التعبيرية لدي للتعبير عن ذاتي & rq & $1 \varepsilon$ \\
\hline متوسطة & 1.380 & 2.71 & 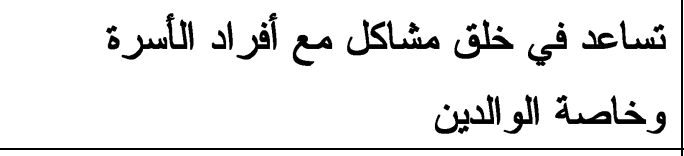 & 0. & 10 \\
\hline متوسطة & .964 & 3.07 & الآثار السلبية لوسائل التواصل الاجتماعي & & \\
\hline
\end{tabular}

يبين الجدول (T) ان المتوسطات الحسابية تراوحت مابين (2.71-3.52)، حيث جاءت الفقرة رقم (0) والتي تتص على "تثسبب في ضياع وقتي " في المرتبة الأولى وبمتوسط حسابي بلغ (3.52)،

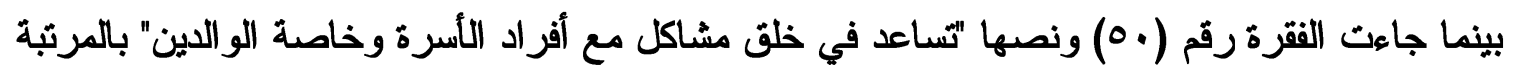

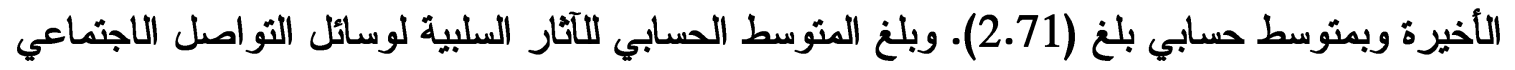

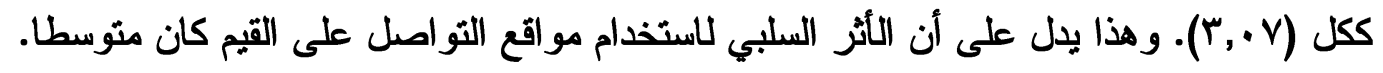




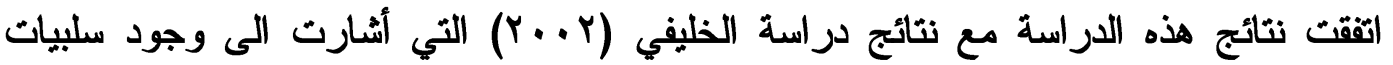
لاستخدام شبكة الإنترنت، من هذه السلبيات انتشار المشاكل الاجتماعية والأخلاقية، كما أن لها دورا واضحا في الغزو الثقافي، وقد يعزى ذلك إلى سعة انتشار وسائل التواصل الاجتماعي وتعلق الأشخاص

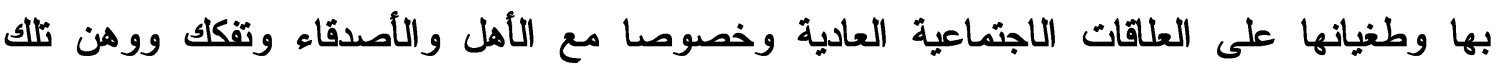
العاقات بسبب الاستخدام الواسع لهذه الوسائل، وطغيان العالم الافتر اضي على العالم الواقعي.

السوال الرابع: هل توجد فروق ذات دلاكلة إحصائية ( 0 =0•, • ) أثر شبكات التواصل الاجتماعي في تفير القيم الاجتماهية للى طلبة جامعة عمان الأهلية تعزى للمتفيرات الديموفرافية: الجنس، والكلية والسنة الدراسية2

للإجابة عن هذا السؤال تم استخدام T-test الخاص بالفروق بين أفراد العينة حسب متغيرات الجنس( النوع) والكلية. والجدول (V) يبين ذلك.

(V) ( )

نتائج اختبار "ت " لاختبار دلالة الفروق في المتوسطات الحسابية لشبكات التواصل الاجتماعي في تغيير القيم الاجتماعية لدى طلبة جامعة عمان الأهلية حسب متغيرات الجنس والكلية

\begin{tabular}{|c|c|c|c|c|c|c|}
\hline مستوي الدلالة & قيمة ت & العدد & الانحر اف & الحستبي & الفئات & المتغير \\
\hline \multirow[t]{2}{*}{0.944} & \multirow[t]{2}{*}{$\cdot, \cdot \times l$} & 56 & .436 & 4.05 & ذكر & \multirow[t]{2}{*}{ الجنس } \\
\hline & & 44 & .513 & 4.13 & انثى & \\
\hline \multirow[t]{2}{*}{0.421} & \multirow[t]{2}{*}{0.828} & 59 & .491 & 4.14 & علمية & \multirow[t]{2}{*}{ الكلية } \\
\hline & & 41 & .430 & 3.99 & انسانية & \\
\hline
\end{tabular}


بالنظر الى الجدول (V) الذي يوضح نتائج اختبار "ت "للعينتين المســنقلثين للمقارنـــة بــين

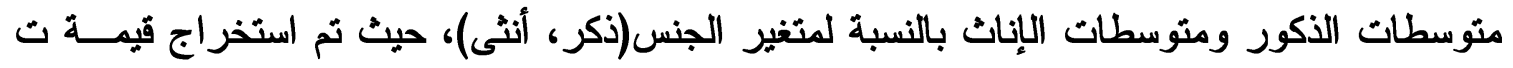
وتساوي § 9, . ، ، ومستوى الدلالة يساوي ال •,. . وهي قيمة غير دالة إحصائيا، ويدل ذلك على عدم

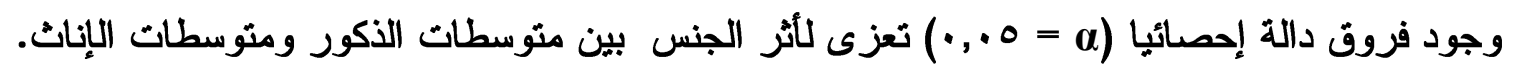
كما تم إجراء اختبار ت للعينتين المسنقلثنين للمقارنة بين متوسطات طلبة الكليات العلمية، ومتوسط طلبة البنة

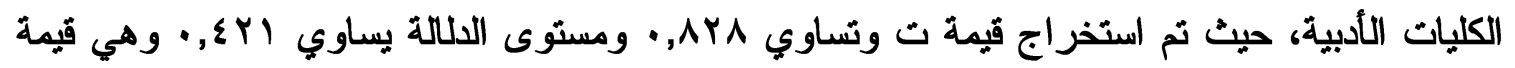

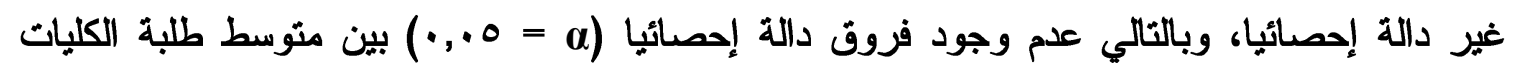
العلمية ومتوسط طلبة الكليات الانسانية، تعزى لائر متغير الكلية.

كما تم استخدام المتوسطات الحسابية والانحر افات المعيارية لشبكات التواصل الاجتماعي في تغيير القيم

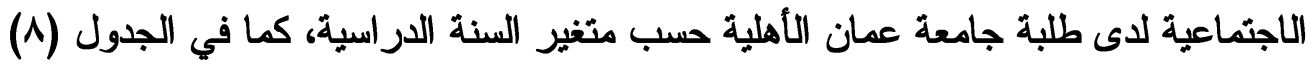

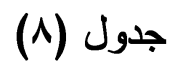

المتوسطات الحسابية والانحر افات المعيارية لشبكات التو اصل الاجتماعي في تغيير القيم الاجتماعية لدى طلبة جامعة عمان الأهلية حسب متغير السنة الدراسية

\begin{tabular}{|c|c|c|c|c|}
\hline العدد العد & الانحراف & المتوسط الحسابي & الفئات & المتغير \\
\hline 19 & .413 & 3.88 & 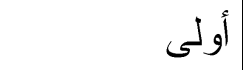 & السنة الدر اسية \\
\hline 22 & .494 & 4.08 & ثانية & \\
\hline 28 & .407 & 4.06 & | ثالثة & \\
\hline 31 & .512 & 4.23 & ر رابعة فأكثر & \\
\hline
\end{tabular}

كما تم استخدام تحليل الثباين الأحادي لمعرفة الفروق بين المتوسطات بالنسبة للسنة الدراسية كما يبين

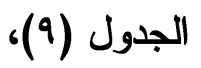

جدول رقم (9)

تحليل التباين الأحادي لأثر السنة الدراسية على شبكات التواصل الاجتماعي في تغيير القيم الاجتماعية لدى طلبة جامعة عمان الأهلية 


\begin{tabular}{|c|c|c|c|c|c|}
\hline الإحصائية & قيمة ف & المربعات & الحرية & المربعات & مصدر التباين \\
\hline \multirow[t]{3}{*}{.139} & \multirow[t]{3}{*}{1.875} & .398 & 3 & 1.195 & السنة الدر اسية \\
\hline & & .212 & 94 & 19.958 & الخطأ \\
\hline & & & 99 & 21.944 & الكلي \\
\hline
\end{tabular}

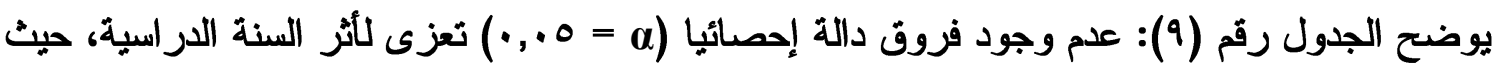

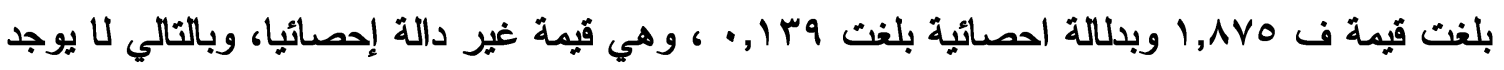

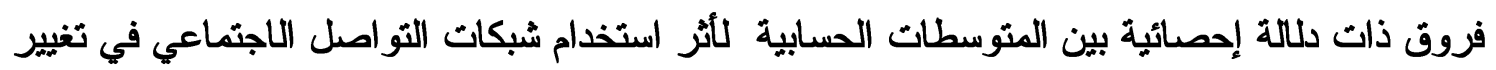
القيم الاجتماعية لدى طلبة جامعة عمان الأهلية بسبب اختاف السنة الدراسية.

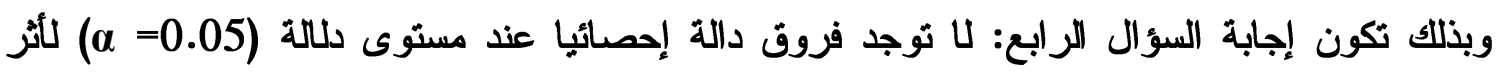

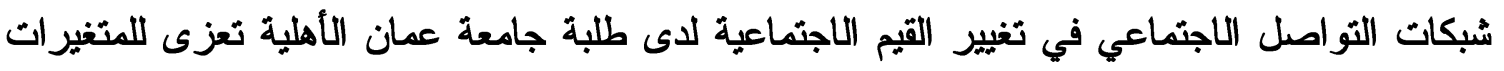
الديموغرافية: الجنس، والكلية والسنة الدراسية. ويمكن تفسير هذه النتيجة بأن طلبة الجامعة من ذكور

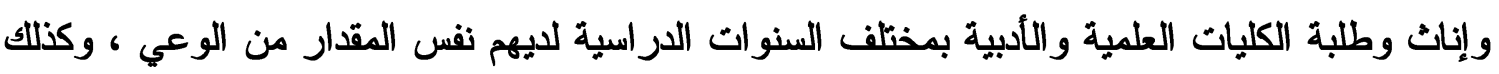
مدى تمسكهم بالقيم الاجتماعية. اختلفت نتائج هذه الدراسة مع نتائج دراسة أبو عيطة، والمشهداني (2004) التي أشارت نتائجها إلى أن

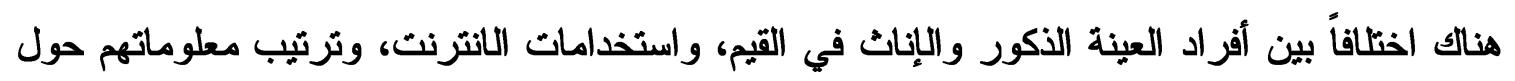
الانترنت وفق: المتغيرات التالية: لتخصصات العلمية، وسنوات الدراسية.

\section{توصيات الدراسة:}

ا.إجراء المزيد من البحوث والدراسات التي تهدف إلى معرفة القيم الإيجابية المكتسبة باستخدام

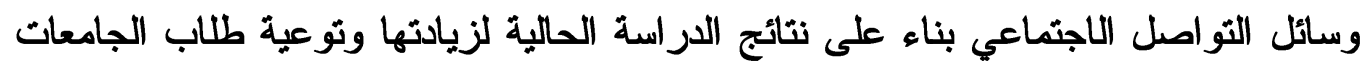

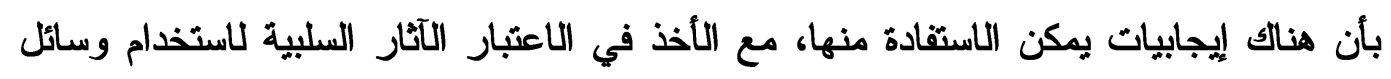

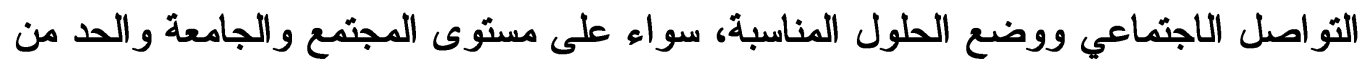
تلك السلبيات. 
r.في الجامعات يجب تحديد المواقع التي يمكن الوصول اليها والمعلومات المسموح الاطلاع عليها من قبل الطلبة. r.عمل الندوات العلمية والمحاضرات وبرامج التوعية، والبرامج التعليمية الهادفة التي توضح لطلاب الجامعة الثأثير السلبي لشبكات التواصل الاجتماعي على القيم الاجتماعية.

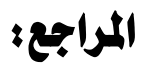

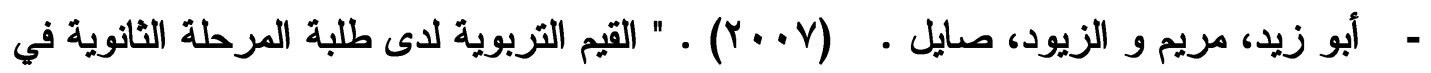
محافظة عمان كما يراها الطلبة أنفسهم"، مجلة دراسات في العلوم التربوية، الجامعة الأردنية،

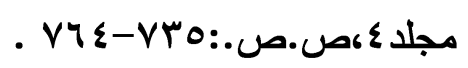

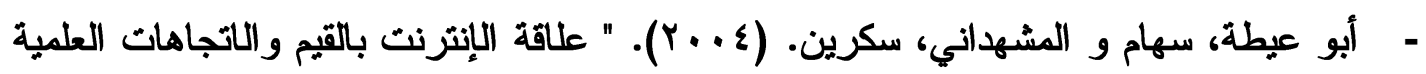

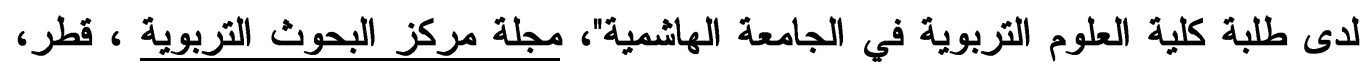

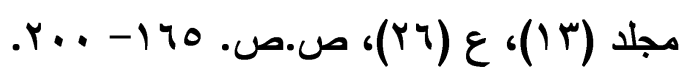

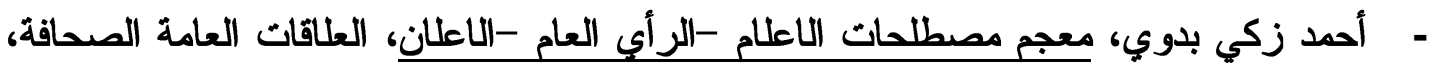

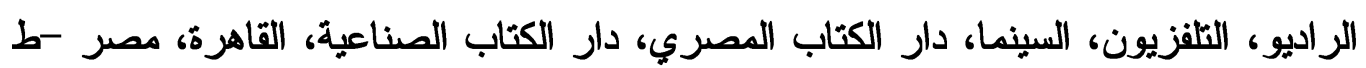

- أسعد، عمرو. (11) " "العلاقة بين استخدام الشباب المصري لمواقع التواصل الاجتماعي

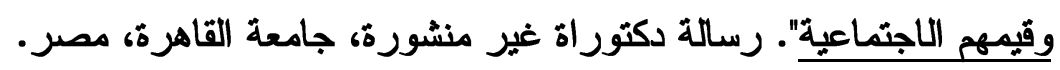

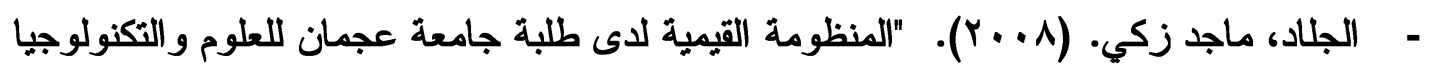

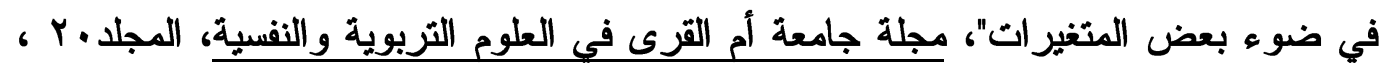

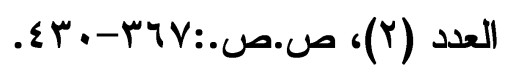

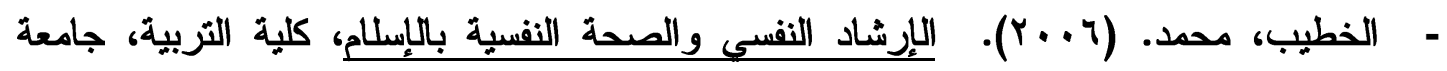
الأز هر، غزة، فلسطين.

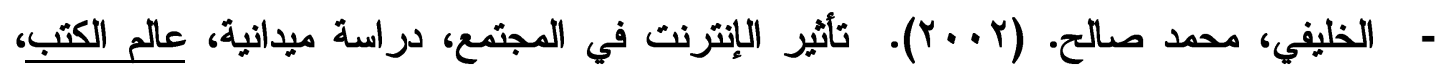
السعودية، المجلد Y، العددان 0 ،7، ص.ص. 


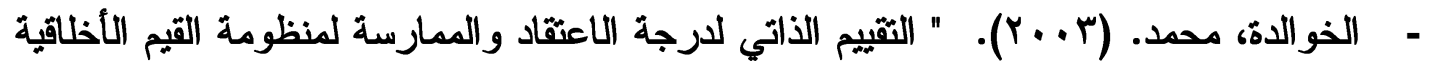
الإسلامية لدى الطلبة في جامعة اليرموك"، مجلة دراسات في العلوم التربوية، جامعة اليرموك،

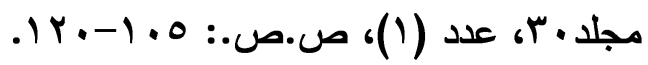

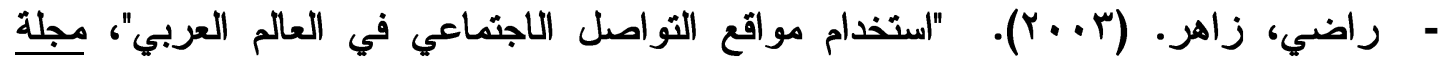
التربية، عه ا، جامعة عمان الأهلية، عمان.

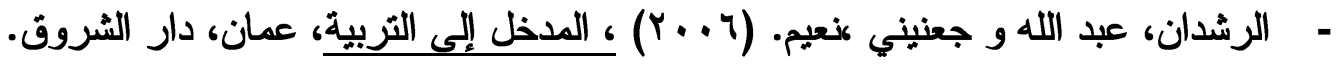

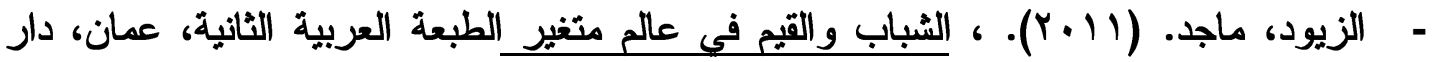

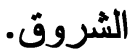
- سرور، هناء. (10 (Y). "وسائل التواصل الاجتماعى وإثراء المحتوى القومى للتمية

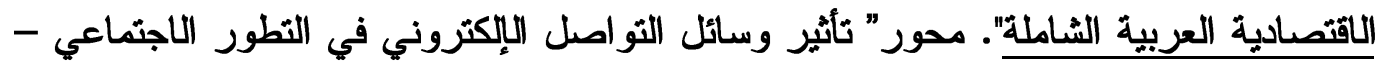
الاقتصادي"-مؤتمر جامعة الدول العربية.

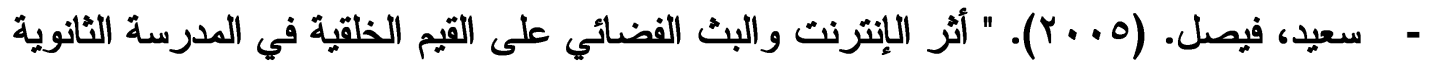
بالمملكة العربية السعودية في عصر العولمة، دراسة ميدانية من وجهة نظر معلمي ست مدارس ثانوية بمنطقة الباحة التعليمية"، مجلة كليات المعلمين، مجلد 0، عدد (Y) أغسطس،

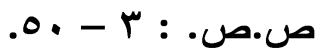

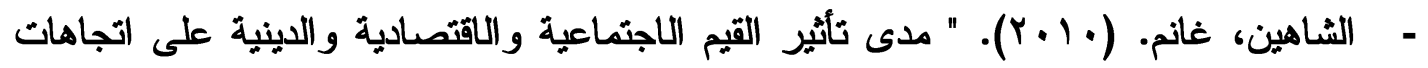
الطالبات المعلمات في مؤسسة إعداد المعلم نحو مهنة التّريس"، مجلة العلوم الثربوية و النفسية،

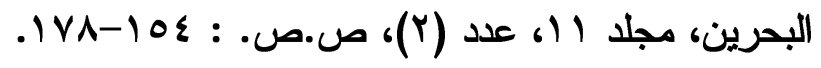

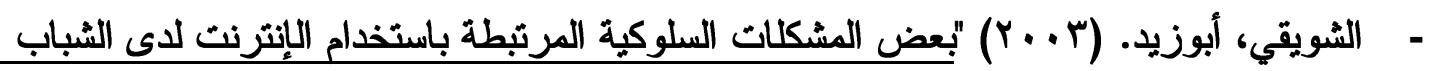

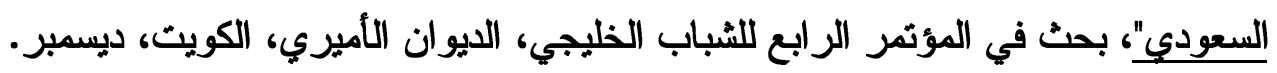

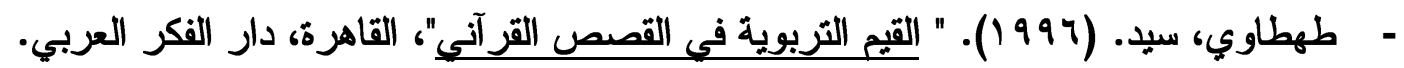

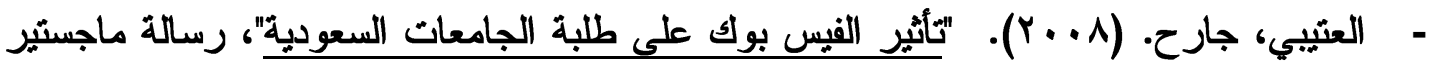
غير منشورة. الرياض، كلية الاداب، جامعة الملك سعود.

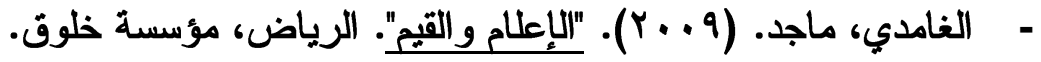

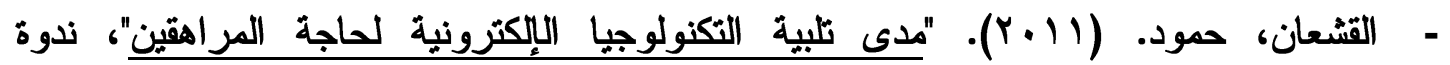
مستجدات الفكر الإسلامي التاسعة: تحت عنوان الإعلام القيمي بين الفكر والتجربة. وزارة الأوقاف و الشؤون الإسلامية. جامعة الكويث. 


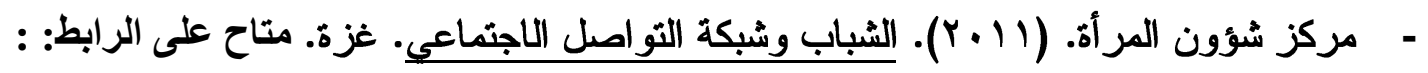
Http: //www.yaf3press.net/Displayasp?pag.)e=2000\&NewsID=1209

\section{المراجع الاجنبية}

- Hinduja, S., \& Patchin, J. W. (2008). Cyberbullying: An exploratory analysis of factors related to offending and victimization. Deviant behavior, 29(2), 129-156.

- Macgill, A. R. (2007). Parent and teenager Internet use. Pew Internet \& American Life Project. http: //www.pewinternet. Org/media/files/Reports/2007pip Teen Parents data memo Oct2007, pdf. 